\title{
An Assessment of Effectiveness of Drug Rehabilitation Programs in Kisii County- Kenya
}

\author{
Ben Nyachwaya Sereta*, Fred A Amimo, Peter Ouma and Thomas Orind Ondimu
}

Health Science, Jaramogi Oginga Odinga University of Science and Technology, Nairobi, Bondo, Kenya

*Corresponding author: Ben Nyachwaya Sereta, Health Science, Jaramogi Oginga Odinga University of Science and Technology, Nairobi, Bondo, Kenya, Tel: +254724497216; E-mail: seretaben@gmail.com

Rec date: Dec 26, 2015; Acc date: Feb 15, 2016; Pub date: Feb 17, 2016

Copyright: ( 2016 Sereta BN, et al. This is an open-access article distributed under the terms of the Creative Commons Attribution License, which permits unrestricted use, distribution, and reproduction in any medium, provided the original author and source are credited.

\begin{abstract}
According to the World Drug Report, approximately 200 million people, about $5 \%$ of the World's population aged between 15 and 64 years have either been forced or voluntarily sought the help of rehabilitation centers for behavioral modifications [1]. These rehabilitation centers over the years have admitted drug addicts into their rehabilitation programs meant to bring about behavior change among the rehabilitees. However, little is known about the effectiveness of drug rehabilitation programs on behavior modification of drug addicts in rehabilitation centers in Kisii County and its environs. Subsequently, no one has established whether the existing rehabilitation programs put in place to help the drug addicts are functional. The study employed the cross sectional design as a method of data collection. The study population was the staff and the rehabilitees of purposively sampled ten rehabilitation centers in Kisii County and its environs. A pre-test was carried out in three randomly selected rehabilitation centers which were not to be part of the final study group.
\end{abstract}

Questionnaires were used as tools for collecting data, one for the staff and questionnaire-guided interviews for the rehabilitees. Data was coded and entered in to the Statistical Package for Social Scientists (SPSS Ver. 10) software and descriptive statistics such as frequencies and percentages calculated. The study employed the matrix model to achieve its objectives. The study sought to prove the Cognitive Theory which has profound implications for the rehabilitees in rehabilitation centers in Kisii County and its environs.

The study mainly found that; Drug users 'evaluation in terms of assessment emerged the key programs offered by rehabilitation centers in Kisii County and its environs; staff members in rehabilitation centers in Kisii County were sufficiently trained, with a good number of them holding degrees, diplomas and certificates from reputable institutions. They also possess proficiency in drug management and rehabilitation tasks. Rehabilitation centers in Kisii County and its environs carried personal continuing / aftercare services to their clients using psychological interventions, and individual personal empowerment of the rehabilitee. Financial impediments like lack of sufficient staff, medication and facilities as well as inconsistent follow ups are major challenges facing rehabilitation centers in Kisii County. These challenges can only be curbed by sufficient funding of these institutions to enable employment of adequate staff and acquisition of better infrastructure to enable enhanced individual attention to rehabilitees. The study recommended that; rehabilitation centers management should foster establishment and implementation of a comprehensive drug rehabilitation schedule that caters to the individual needs of a rehabilitee and at the same time manage rehab time to avoid boredom among the patients. Rehabilitation centers staff should gain insights on various needs of the rehabilitees to avoid unnecessary strife in the rehabs. They should also learn to handle the rehabilitees with professionalism to enable a successful rehabilitation process. Rehabilitees in the rehabilitation program should also learn a number of personal management tips to help them adequately plan for and make the most out of personal management tips for the period they are in the rehab center. The ministry of special programs should look into various problems encountered by staff and clients in rehabilitation centers. The ministry should then formulate policies on the funding and staffing of these centers to facilitate a sound drug rehabilitation process.

Keywords: An assessment; Drug; Rehabilitation; Programs

\section{Introduction}

\section{Background to the study}

The use of drugs has been around since time immemorial. People have used drugs for various purposes depending on culture and activities at hand. At most drugs have been known to bring euphoric feelings that change moods of people to pleasurable feelings especially in social celebrations and when people are operating under tension [2]. Because of their ability to relief tension many people use drugs and with the stressful life associated with challenges in contemporary society the number has been on the increase. Hence initiating the use of drugs is always associated with the benefits that it brings to the users.

However, eople who use drugs experience a wide array of physical effects other than those expected. Marijuana and alcohol for example, interfere with motor control and are factors contributing too many automobile accidents. Users of marijuana and hallucinogenic drugs may experience flashbacks, unwanted recurrences of the drug's effects weeks or months after use. Abrupt abstinence from certain drugs results in withdrawal symptoms. For example, a heroin withdrawal 
symptom causes vomiting, muscle cramps, convulsions, and delirium [3]. The excitement of a cocaine effect, for instance, is followed by a "crash": a period of anxiety, fatigue, depression, and a strong desire to use more cocaine to alleviate the feelings of the crash [4]. This is due to its addictive nature that lures the users into over use. The after effects of drugs and the assumption that relief can only be used in continuous use of drugs leading to increased drug abuse and dependence with many negative psychosocial effects. With the continued use of a physically addictive drug, tolerance develops; i.e., constantly increasing amounts of the drug needed to duplicate the initial effect. Because the purity and dosage of illegal drugs such as heroin are uncontrolled, drug overdose is a constant risk. Many drug users engage in criminal activity, such as burglary and prostitution, to raise the money to buy drugs, and some drugs, especially alcohol, are associated with violent behavior [4].

Therefore one of the greatest concerns in many countries today is the rapidly rising number of drug users worldwide. According to the World Drug Report [1] and Sacks [5] the total number of drug users in the world is now estimated at some 200 million people, equivalent to about 5 percent of the global population [6]. The UNODC estimates that between 155 and 250 million people $(3.5 \%$ - 5.7\% of the population aged 15-64) use illicit substances at least once. Consequently it is estimated that there are between 16 and 38 million 'problem drug users' every year.

The abuse of drugs in Africa is nevertheless escalating rapidly from cannabis abuse to the more dangerous drugs and from limited groups of drug users to a wider range of people abusing drugs [7]. The most common and available drug of abuse is still cannabis, which is known to be a contributing factor to the occurrence of a schizophrenic-like psychosis [8]. Regionally according to Kilonzo et al. [9] a rapid situation assessment carried out in five Tanzanian towns found heroin to be a major concern. Just like other parts of the world, Kenya has experienced upsurge in number of drug and substance abuse.

In Kenya more worrisome statistics came from a NACADA Authority survey that showed about $40 \%$ of Kenyans aged between 15 and 65 years have drank one type of alcohol or another, and that at least $13 \%$ of people from all provinces in Kenya except in the North Eastern region are current consumers of alcohol. The vast majority of drug users are the youth. The 2007 study found that alcohol is abused by $77 \%$ of youths out of school and $28 \%$ of youths in school. It also established alcohol, tobacco and bhang as being the most easily known abused substances by over $50 \%$ of $15-65$ year-olds. The trend is worrying to many policy makers, parents and society at large.

Drug abuse has invaded homes, schools and work places affecting individuals of all ages and classes [10] Mouti argues that this disturbing scenario has largely been caused by high rates of unemployment, media influence on the youth, breakdown of African traditional system that had checks and balances on individuals' behavior, poverty and ignorance of the effects of drugs. In a nutshell drugs have many negative effects to the individual, family and society at large. In this regard communities all over the world have been preoccupied with search for programs to help those affected by drugs. Different societies worldwide have sought different ways of assisting those addicted to change their behavior. It is from this understanding that rehabilitation program are crucial as intervention measures arises for behavior modification [11]

According to the World Drug Report [1] approximately 200 million people, about $5 \%$ of the world's population aged between 15 and 64 years have either been forced or voluntarily sought help of rehabilitation centers for behavior modification. According to surveys carried out in 1991 and 1996 among adolescent students in Nova Scotia in Canada, over one fifth (10.9\%) of the students reported to have used alcohol, tobacco and cannabis underwent rehabilitation programs [12].

The first use of the term 'behavior modification' appears to have been used by Edward Thorndike. In his article, Provisional Laws of Acquired Behavior or Learning, he makes frequent use of the term "modifying behavior". He argues that behavior in human beings can be modified through effective programs. Historically, rehabilitation programs in relation to behavior modification can be traced to First World War in Germany. The soldiers who were involved in the war and were able to survive, experienced traumatic experiences which resulted in drug taking and later on addiction. About 5,000 soldiers who were addicted and accepted to join rehabilitation programs, showed signs of improvement after four months [13]. He further indicates that three quarters fully recovered after six months while a quarter went back to same habit after leaving the rehabilitation centers. European community project on alcohol and other drugs is another example where rehabilitation of drug addicts has been successful in behavior change. $17 \%$ of community members successfully underwent rehabilitation programs. For example study conducted in Mexico to find out the success of rehabilitation programs on drug rehabilitees found out that after care programs by the immediate family and the community around rehabilitees played a bigger role in reducing relapse cases. The implication is that effective rehabilitation programs can work for the good of the community.

Rehabilitation programs have since, come to refer, mainly to techniques for increasing adaptive behavior through reinforcement and also decreasing maladaptive behavior through extinction or punishment. Meltenberger (2008) describes rehabilitation as behavioral interventions designed to influence the behavior change of people or individuals in a way that benefits them and the society at large [14]. Drug rehabilitation, according to Higgins [15] is the processes of medical or psychotherapeutic treatment, for dependency on psychoactive substances such as alcohol, prescription drugs, and socalled street drugs such as cocaine, heroin or amphetamines. Dependency in this case means a situation where a rehabilitee is unable to do without a specific drug. The main intention of drug rehabilitation is to help addicted individuals stop compulsive drug seeking and use. In addition to stopping drug abuse, the goal of treatment is to return people to productive functioning in the family, workplace, and community. The ultimate goal of drug rehabilitation centers is therefore to create opportunity for behavior change through helping the drug addicts to curb psychological, physical and emotional problems brought about by the drugs.

Scientific research since 1970 shows that effective rehabilitation programs address drug addiction and health related complications of the addict person. Professionals from the National Institute on Drug Abuse (NIDA) recommend medication and behavioral therapy combined, as important elements of a therapeutic process that begins with detoxification that follows with treatment and doesn't set aside prevention of relapse, since this is essential to maintain the positive effects of therapy. Behavioral therapy requires individuals to admit their addiction, renounce their former lifestyle, and seek a supportive social network who can help them remain sober while detoxification method gets toxins out of the body that causes cravings, anxiety, and depression. 
Just like other parts of the world, Kenya has experienced upsurge in number of drug addicts that has forced the government, nongovernmental organizations, religious and individuals to come up with rehab centers offering rehabilitation programs meant for behavior modification. These rehabilitation centers over years have admitted drug addicts into their rehabilitation programs meant to bring about behavior change among the rehabilitees. However, little is known about the effectiveness of the programs offered. This study therefore examines the effectiveness of rehabilitation programs on behavior modification of drug addicts in Kisii County.

\section{Statement of the problem}

The problem underlying this study was that, although there have been different programs in different rehabilitation centers meant for behavior modification among drug addicts in Kenya, little is known about their effectiveness. Drug rehabilitation centers worldwide are mainly meant to offer programs that modify behaviors of the rehabilitees specifically to enable the rehabilitee to stop using drugs. The programs are designed to address the needs of the drug addicts to help bring about the desired permanent change in behaviors among the rehabilitees and prevent going back to the vice. But studies for example Otieno noted that most drug addicts revert to the vice after treatment. He cites insufficient psychological care during and after treatment as the reasons that contribute to relapse. However, he does not state whether the inefficiency is a result of programs offered or other factors

Recently, over 30 drug addicts volunteered to seek rehabilitation services in Mombasa. They were received and enrolled into the program. However, after a week, the rehabilitees complained of lack of basic amenities and treatment for their condition. Three quarters of them dropped from the rehab centre and went back to drugs. However, it is unclear to what specific issues about the program led them to pull out. Studies have been done on factors contributing to one to seek rehabilitation services, programs offered in rehab centers but little has been done to establish the effectiveness of the programs on behavior modification.

\section{Purpose of the study}

This study therefore filled the gap by examining the effectiveness of programs offered in rehabilitation centers in relation to behavior modification of drug addicts by establishing how drug rehabilitation programs can be improved to help bring about effective treatment.

\section{Broad objective}

The study established the effectiveness of rehabilitation programs in relation to behavior modification of drug addicts in rehabilitation centers in Kisii County and its environs.

\section{Specific objectives}

The following specific objectives guided the study:

The study identified types of programs offered in drug and substance rehabilitation centers in Kisii County and its environs.

It assessed the effectiveness of the programs in addressing the needs of drug addicts

It assessed the capacity of service providers (staff) to offer rehabilitation services in rehabilitation centers.
The study described challenges influencing the effectiveness of rehabilitation programs

The study proposed strategies to improve the effectiveness of the programs in existing rehabilitation centers.

\section{Research questions}

The study was guided by the following research questions:

What are the types of programs offered in drug rehabilitation centers in Kisii County and its environs?

In what ways do the rehabilitation programs in rehabilitation centers effectively address the needs of the addicts?

How adequate are the staff capacities to offer rehabilitation services in rehabilitation centers?

Which factors hinder effectiveness of rehabilitation programs in Kisii County and its environs?

How can the effectiveness of the programs in rehabilitation centers be improved?

\section{The significance of the study}

The study enabled the rehabilitation centers understand the effectiveness of the rehabilitation programs they are offering to rehabilitees. The government, non-governmental organizations, religious organization and other stakeholders based on the findings of this study may review the existing programs to make them beneficial to rehabilitees. These stakeholders found it necessary to put in place legislations and policies that guided establishment and management of rehab centers. It was anticipated that more studies will conducted in the area of rehabilitation programs that was enhance behavior modification among drug addicts. This study was limited to Kisii County.

\section{Justification of the study}

Drug abuse and addiction are a threat to the survival of the society. Therefore the increasing rate of drug problem in the society is a concern to all people. Through rehabilitation programs, people who are addicted to drugs can be assisted to change their behavior. However, it is only effective programs that can bring about behavior change. Understanding the effectiveness of the rehabilitation programs used could be achieved through an empirical study in which the strengths and the weakness are identified and analyzed. This can be able to inform the service providers on areas that need to be improved to enhance their ability in bringing about behavior change. It is for this reason that this study on the evaluation of effectiveness of current existing rehabilitation program was found justified.

\section{Scope and limitations}

This study confined itself to effectiveness of rehabilitation programs among drug addicts in rehabilitation centers in Kisii County and its environs only. Information was sourced from rehabilitees admitted in rehab centers within Kisii County on effectiveness of the rehabilitation programs on behavior modification.

The findings of this study are only applicable to Kisii County or other areas with similar characteristics. The researcher anticipated that there would be some inconsistency in provision of information and 
lack of co-operation by rehabilitees who have still been having psychological challenges in rehabilitation centers. However, the researcher incorporates Psychologists, Counselors and other service providers in the centers in offering any necessary assistance to the rehabilitees. This way, the level of inconsistency is minimized.

\section{Literature Review}

\section{Introduction}

In reference to the study on effectiveness of drug rehabilitation centers in Kisii County and its environs, this chapter presents an up to date review of related literature. The literature was sourced from relevant professional education journals, and published papers. The chapter is divided into the following sections: Introduction, theoretical framework, review of related literature, and conceptual framework.

\section{Theoretical frame work}

The study was based on Cognitive behavioral theory which has profound implications for persons with drug and substance abuse disorders.

Cognitive behavioral theory: Cognitive behavioral theory by Aaron Becks approach emphasize teaching clients self-management skills and how to restructure their thoughts, the clients learn to use these techniques to control their lives to deal effectively with present and future problems and function well without ongoing therapy. According to Fatoye [16] cognitive processes cover numerous mental activities such as beliefs, ideas, schemas, values, opinions assumptions among others that are likely to lead addictive behaviors including anticipatory beliefs, relief oriented beliefs, automatic thoughts facilitative beliefs and instrumental beliefs. This cognitive process interacts with the emotional, environmental, physiological and developmental processes to determine if a person will manifest addictive behaviors. For example, as highlighted earlier in the background, most people initiate taking of drugs in anticipation of feeling good, relieving of stress and forgetting about the challenges they may be facing in life. Lesie et al. [17] argue that most addictive behaviors can be traced to various activating stimuli also known as triggers which could be both internal and external. Internal triggers are mostly experienced as emotions e.g., anxiety, depression anger or boredom) or physiologic sensation (fatigue, pain, tension). People use addictive behavior as compensatory strategies to regulate and cope with feelings. For example, many people get into drugs when they join groups to relieve boredom, to relieve anxiety and depression External cues include exposure to addictive substances, people and places. Many addicted youth feel helpless about urges and cravings they associate with external cues.

Cognitive behavioral addiction treatments focus on modifying thoughts and behavior and developing coping skills. Some of the goals of cognitive theory are teaching clients about relapse prevention strategies, coping with anxiety disorders and managing stress disorders. These are vital treatment programs for persons with drug and substance abuse disorders which include depression, social behaviors and other maladaptive behaviors that lead to drinking and taking drugs. Therefore according to this theory an effective program should help clients to understand the consequences of defective thinking and be assisted through restructuring their self-concept to evade incongruence which undermines their psychological wellbeing. Psycho education and skill building mood control, motivation and readiness to change, crisis management and finding meaning in life are some of the areas to be emphasized in skill training to assist drug addicts in maintaining healthy behaviors [17]. In addition Jone [18] states that Most drug addicts feel wounded, neglected and need love, empathy and conducive or less threatening environment to respond positively to therapeutic processes. The programs should also carter for emotional needs if they have to facilitate healing among drug addicts. Essentially, most patients can benefit from treatment delivered in either in- or outpatient settings, although specific subgroups seem to respond optimally to particular environments.

The cognitive behavioral theory found its entry into the current study due to its basic assumption that most problematic behaviors, cognitions and emotions have been learned and can be modified by new learning. Ben came up with a view that people need to cast aside their self-defeating or negative thoughts and replace them with the positive ones. This process results to liberation of the mind from dependence on drugs and substances, leading to positive behavioral modification. Cognitive theory techniques enhance self-control which is vital for rehabilitees to remain sober.

\section{Drug and substance abuse}

A base line survey NACADA [19] on drugs and substance abuse targeting 10-24 years old youth indicate that the trend for drug and substance abuse is on the increase. Drug and substances of abuse have direct consequences on the users some use them to overcome problems and or cope up with some challenging issues in their lives. Drug abuse refers to the use of illegal drugs or the inappropriate use of legal drugs. According to NACADA [19] the commonly abused drugs and substance by Kenyan youth include: - alcohol, tobacco, miraa, bhang, host of inhalants and prescription drugs. Personality factors, genetic factors and environmental influences are important determinants of drug and substance abuse in Kenya.

The United Nations office on drug and crime (UNODC) has supported several studies on drug abuse in Kenya [10]. One of the studies, 'A rapid assessment points out that the drug abuse problem has permeated all levels of society with the youth and young adults being most affected [19].

\section{Factors contributing to drug taking}

The major factor among the youth is peer pressure, instigated by need for acceptance and approval from their peers. Peer pressure accounts for $21-42 \%$ influences in all types of drugs and substance consumed. Curiosity for reason of experiencing the Euphoria associated with certain drugs a person may be tempted to use drugs and substance accessible. In the process of satisfying curiosity an individual ends up being hooked. Curiosity accounts for the highest influence which ranges from 23-48\% NACADA [10] Stress is another factor influencing the use of drug and substances as a way of running away from problems or harsh realities of life (United Nations Office on Drugs and Crime). Stress could be precipitated by poor job design, financial problem, family problem, poor academic performance, poverty and other depressive issues. Family negligence or instability may drive some members to taking drugs and substances as a way of escaping the realities of life. Lack of parental love and guidance lack of basic necessities may make children to join the street families ending up inhaling solvents, glue and using drugs to cope up with frustration. Social occasion accounts for $35.4 \%$ of the reason for taking alcohol this is due to the esteem that most societies associate with taking alcohol at party times. 
Effects of drugs: Drug abuse, also called substance abuse or chemical abuse, is defined by McCance-Katz as a disorder that is characterized by a destructive pattern of using a substance that leads to significant problems or distress [20]. On the other hand, drug addiction, also called substance dependence or chemical dependency, is a disease that is characterized by a destructive pattern of drug abuse that leads to significant problems involving tolerance to or withdrawal from the substance, as well as other problems that use of the substance can cause for the sufferer, either socially or in terms of their work or school performance [21].

The abuse of drugs in Africa is nevertheless escalating rapidly from cannabis abuse to the more dangerous drugs and from limited groups of drug users to a wider range of people abusing drugs. The most common and available drug of abuse is still cannabis, which is known to be a contributing factor to the occurrence of a schizophrenic-like psychosis [8].

Drugs and substance abuse has both short and long term effects on the users. A meeting held in August, 1991 in Mombasa by preventive health education against drug abuse outlined the effects of drugs in three categories; health, social and economic on the individual, family, community and the nation. Drugs damage body organs causing loss of self-control, emotional instabilities leading to maladaptive behavior; financial problems become evident as health care cost rises because of treating and rehabilitating the users. Due to effects on the health, loss of job due to constant absenteeism leads to low productivity hence loss of income which contributes to poverty.

\section{Rehabilitation programs}

According to Roberts's rehabilitation programs is a term for the processes of medical and/or psychotherapeutic treatment, for dependency on psychoactive substances such as alcohol, prescription drugs, and so-called street drugs such as cocaine, heroin or amphetamines. The general intent is to enable the patient to cease substance abuse, in order to avoid the psychological, legal, financial, social, and physical consequences that can be caused, especially by extreme abuse of drugs [21].

There are many rehabilitation programs for drug and alcohol addiction. These programs include: Assessment of drug users which entails brief history of the substance in use, any past treatment and mental status examination. This should be done before any treatment program is drawn for the client (drug addict), self-management programs and self-directed behavior which includes teaching the rehabilitees how to live a self-directed life and not to be dependents, counseling which will help people identify their problems and how to cope with them, individualized treatment plan, pharmacotherapy and medical care which deals with physiological effects of drugs which need medication such as detoxification, and relapse prevention techniques is to help the rehabilitees remain sober after being discharged from the rehabilitation centers NACADA [6].

One objective of the study was to find out whether the human and infrastructural resources are enough and adequately trained to offer appropriate services to the rehabilitees. The rehabilitees and rehabilitators should cooperate to ensure that the rehabilitation process is effective. Regular physical and social activities in the postrehabilitation period are necessary for relapse prevention [22] and that is why infrastructural resources is important for recreation activities.

Assessment of drug users: In behavioral therapy the function and role of therapist is to conduct thorough functional assessment to identify the maintaining conditions by systematically gathering information about the situational antecedent, the dimension of the problem behavior and the consequences of the problem. This guide to formulate initial treatment goals, design and implement a treatment plan to accomplish these goals. According to National Standards for treatment and rehabilitation of persons with substance use disorders NACADA [6] client assessment should be done immediately a client is accepted or admitted in a rehabilitation treatment centre. The assessment comprises of assessing the physical and psychological functioning of the client which include Mental Status Examination (MSE) so that relevant therapeutic plan is arranged for the specific rehabilitee.

The services of the counselor are also of significance here. Before assessment, the counselor should engage with the rehabilitee. One on one encounter between the rehabilitee and the counselor assists the rehabilitee to accept his or her problem, and his / her need for help. According to NACADA no treatment- in this case meaning drug rehabilitation therapy- should be administered to any client before assessment which entails a brief history of client, the substance in use, any past treatment, risk potential for instance suicidal attempts and mental status examination (MSE). This forms the baseline of coming up with an appropriate treatment plan to address the actual problems of the rehabilitee. The objective of assessment is mainly to understand the impact substance abuse has had on the individual, identify problems to be addressed in treatment programs and match the participant to appropriate levels and types of substance abuse services to enhance recovery the process. The rehabilitees should be put in a program that helps them change their maladaptive behaviors and be able to practice them even after leaving the centers to avoid relapse. Established specialized substance abuse treatment programs which have three similar generalized goals namely:

Reducing substance abuse or achieving a substance-free life

Maximizing multiple aspects of life functioning

Preventing or reducing the frequency and severity of relapse

In a study to establish appropriate intervention measures for curbing drug addiction in Meru County observed that majority of studies focused on the effects of drug abuse but not assessing the causes of drug abuse so that the victims could be helped to lead a normal life. NACADA highlighted in their study of drug addicts in Nyanza province that one of the causes of relapse cases was as a result of poor assessment of addicts prior to their admission in the rehabilitation centers. This observation was vital for this study for it helped the researcher to find the appropriate procedures carried out in rehabilitation centers in Kisii County and its environs. Assessment was the most carried out procedure in rehabilitation centers which the service providers used to base the treatment plan for their clients.

Self-management programs and self-directed behavior: In rehabilitation centers involvement and commitment of the clients in their treatment plan is crucial in behavior change. The client (rehabilitee) should own the treatment plan for change comes from within. This involves psychologists being willing to share their knowledge so that the consumers in this case the drug and substance addicts can increasingly lead self-directed lives and not be dependent on the experts to deal with their problems.

The rehabilitees should be helped to understand that their life is in their hands despite the kind of support they may get from the treatment centers. The centers have programs and forums where clients 
participate in decision making in reference to the programs they are involved in, to help them become aware of what they are doing and get them out of the victim role "May. Rehabilitees should be trained selfmanagement skills for instance being assertive, change their selfsabotaging beliefs and work out on their own given assignment to help change their self-defeating behaviors. One of the factors in existential therapy states and I quote "Learning that I must take ultimate responsibility for the way I live my life no matter how much guidance and support I get from others" Yalom. Rehabilitation centers should have standardized programs to enable rehabilitees to remain sober even after leaving the centers. This can be done through effective after care services. Rehabilitees in treatment should fully participate in all activities designed to achieve the set goals in the treatment plan for them to achieve the desired changes within the given time. Decision making is an important self-management skill; the rehabilitees should be trained on making sound decisions to effect positive behavior change. They should make decisions concerning the behavior they want to change. There are five basic steps of self-management program provided these steps of self-management program provided include: selection of goals which specify behavior to be changed, translating the goal into target behavior, self-monitoring which helps them to observe their own behavior and devising a plan to bring out actual change. Furthermore, they finally need to evaluate an action plan which should be flexible for easy adjustment bearing in mind that evaluation is a continuous process. This thus calls for full participation and commitment of the client (rehabilitee) on therapeutic programs offered in the rehabilitation centers.

Khantzian et al. [23] observes that there can be defects that affect tolerance, distress, tension rage, shame and loneliness that clients may be unable to deal with. These may be caused by irrationally thinking / reasoning. Cognitive theory techniques which emphasize on processing information rationally are very crucial for survival of any organization being inclusive in training self-management skills to drug addicts. The researcher found that more is required to train the rehabilitees to own the programs and manage their self-defeating behaviors.

Counseling in rehabilitation centers: Counseling is a therapeutic intervention which offers support and guidance and is undertaken by relevantly trained accredited and professional staff members NACADA. In rehabilitation; services are offered by interdisciplinary team with a primary counselor assigned to each client at the treatment centre. The counselor who is a professional is responsible for the assessment and ongoing treatment of the client while at the centre. Counselors help individuals to identify behavior problems related to the use of drugs and substance and come up with a recovery treatment plan. According to cites that the therapist functions as teacher and coach, fostering a positive, encouraging relationship with the patient and using that to reinforce positive change. The counselor should apply techniques which alter the irrational thinking beliefs and emotional and behavioral disturbance exhibited by persons with drug and substance abuse disorders.

According to David et al. [24] psychotherapy approach has developed a process of counseling people with drug and alcoholic problem the process involves exploring the patients problem, assisting the client set goals, motivating the client and helping them to maintain the changes they gain in the recovery process. It is believed that the counseling process changes the individual behavior and counselors need to look at the broader framework of the patient's life before starting any therapy session. The Counselor is to apply techniques appropriate to individual clients in reference with the initial assessment reports by the interdisciplinary team in the rehabilitation centers. The counselor in rehabilitation needs to understand the drug and substance abused their effect physically, socially and economically and how they affect the normal functioning of the clients.

Counselors (therapists) are trained to conduct treatment sessions in a way that promotes the client's self-esteem dignity and self-worth. National standards for treatment and rehabilitation of persons with substance use disorders advocate for a professional mental health practitioner to offer services in drug and substance rehabilitation treatment centers.

Individualized treatment plan: Individualized treatment plan (ITP) is one of the programs recommended for treatment of persons with drug and substance disorder. Baker observes that individualized treatment focuses directly on reducing or stopping the addict's illicit drug use through regular monitoring and multiple interventions like behavioural therapy, group counseling, cognitive therapy and medication. It also addresses patient's recovery program by seeking the intervention of family members and the rehabilitee's immediate community on addressing certain external factors that influence the rehabilitee to take up drug abuse and other illicit activities. Individual treatment selection depends on the nature of the substance addiction and psychological condition of the personal preferences, strengths and characteristics and the social needs. The individual plan includes the clients' responsibility and commitment to the rehabilitation process and the type of therapeutic activities the client will be involved. The client should be involved in the plan, to own it and work towards the set goals to eradicate the self-defeating behavior.

Individualized treatment assists in addressing the actual individual problem without generalizing for individuals react differently though using same drugs. Individualized treatment can be a motivator to enhance participation for the clients feels accepted and well understood. Freedom of expression is guaranteed for some individual clients may be shy to share their experiences.

Individualized drug counseling helps the counselor to interact with the patient effectively. During general counseling sessions, patients might find it hard to discuss or disclose some personal information in relation to circumstances that led to use of the drugs. Through its emphasis on short-term behavioral goals, individualized drug counseling helps the patient to develop coping strategies and tools for abstaining from drug use and then maintaining abstinence. However, extensive individualized counseling is important as a form of follow up process that aims at ensuring that the rehabilitees don't go back to their old habits (Peirce). Though individualized treatment is important according to the study findings, most rehabilitation centers prefer group counseling due to lack of adequate staff. This hinders many rehabilitees individual needs not be addressed leading to slow recovery process.

Group counseling: Besides involving counselors in the recovery process, it is equally important to use this method in preventing cases of addiction. Qualified counselors are involved in group counseling where collective counseling is offered to the group [25]. In ensuring that the counselors drive in their points clearly, they may decide to incorporate previous drug and alcoholism recovering addicts in advising the group of the importance of abstaining from drugs.

In drug and substance rehabilitation centers the clients share some similar problems. Group counseling will enable the practitioner work with more clients and especially where there is inadequate staff. Group 
members also benefit from the feedback and insight of other recovering addicts. Persons with drugs and substance disorders experience poor interpersonal relationships so in participating in group therapy the interactions may assist them learn how to establish meaningful and intimate relationships.

Anxiety and depression are common problems associated with drug addicts. This leads to low self-esteem, suicidal attempts and severe psychosis. As the members share their experiences, in group session the recovering drug addict acts as a role model to others who may be in denial or lost hope in life. One of the major goals of group therapy is to increase self-acceptance, self-confidence, and self-respect and achieve a new view of oneself and others. As the addicts interact they gain insight and practice new skills like communication, commitment to the ongoing treatment programs as they hear and observe their fellow group members. Group members through the guidance of therapists, can form support group which can benefit the members after being discharged from the centre. According to the group therapy could be applicable to addicts experiencing resistance by learning to shed off the facade and face the reality of life. Some addicts may be in denial and may be blaming others for their current state.

In conclusion, counseling should focus on growth and development, enhancement of prevention, self-awareness and releasing block to growth. The role of counselors is to ensure that the patients get the required attention especially offering non-judgmental and yet assertive counseling. During the withdrawal process, behavioral symptoms may be experienced and counseling sessions could be of help at this point. It is suggested that more refined counseling need to be offered besides the renowned self-help group counseling. The counselors in such situations are expected to enhance motivation while offering cognitive therapies. Although the decision to withdraw from drugs and alcoholism comes from the victim, some may fail to accept their conditions and this may lead to self-denial that eventually leads to suicide.

The counselors have to be very careful in ensuring that they pay attention the patient's clinical history involving alcohol and drug withdrawal complications. This would help them evaluate on which best approach to use in helping the patient recover effectively. Medical treatment of patients with withdrawal symptoms should go hand in hand with the psychological therapy that is intended to help the patient in coping with problems like depression. For the patient to completely withdraw from addiction, counseling programs should be extended to the family members and friends of the victim. Since the counselors cannot be able to stay with the patient throughout, the immediate people need to be highlighted on how to carefully take care of the patient.

It is very important that the counselor ensures that the patient is discouraged from intermingling with people that may end up influencing them to go back to drugs and alcoholism. In some instances, it's the parents who are affected and this affects the children as well. Therefore, the counseling services should be extended to other family members who may be affected by the withdrawal symptoms by the patient / drug addict in the family, which the researcher found fairly applied by most rehabilitation centers.

Pharmacological intervention: Pharmacological intervention is an individualized treatment and therapy using prescribed drugs. Addiction is abnormal psychological status created by misuse of drugs and substances, pharmacotherapy can provide relief for abnormal psychological disorders which include depression, anxiety and accompanied withdrawal symptoms. Medication is applied to reduce the effects of the drugs which may be pathological. Detoxification is a collective of intervention directed at controlling acute drug intoxication and drug withdrawal NACADA. Detoxification is used on drug addicts while anti abuse is commonly used on alcoholism to revert the effects. Ibogaine is an experimental medication proposal to interrupt both physical dependence and psychological craving to a broad range or drugs including narcotics, stimulants and alcohol Spate.

According to the National Institute on Drug Abuse (NIDA) patient stabilized on adequate sustained dose of methadone can keep their jobs avoid crime and violence and reducing injection drug and drug related high risk sexual abuse. Ant abuse produces a very unpleasant reaction when taking alcohol which includes flushing nausea and palpitation. These disturbing feelings force alcoholic client to stop taking alcohol.

According to NACADA [19] only trained medical clinician should administer medication after intense assessment of the client. Medicine can have adverse severe effects on the client if poorly administered. Close monitoring should be put in place to address any negative reaction.

Relapse prevention: Relapse prevention and management techniques should be emphasized to help clients (rehabilitees) avoid and deal with relapse situations after learning skills at the treatment centers [26]. The relapse prevention approach to the treatment of cocaine addiction consists of a collection of strategies intended to enhance self-control. Specific techniques include exploring the positive and negative consequences of continued use, self-monitoring to recognize drug cravings early on and to identify high-risk situations for use, and developing strategies for coping with and avoiding highrisk situations and the desire to use. A central element of this treatment is anticipating the problems patients are likely to meet and helping them develop effective coping strategies [27]. Research indicates that the skills individuals learn for instance stress management, coping with and avoiding high risk situation which may trigger craving may remain after the completion of treatment.

In one study, most people receiving this cognitive-behavioral approach maintained the gains they made in treatment throughout the year following treatment [28]. Alan describes four psychosocial processes relevant to the addiction and relapse processes: self-efficacy, outcome expectancies, attributions of causality and decision making processes. Self-efficacy refers to one's ability to deal with high risk relapse provoking situations competently and effectively. Outcome expectancies refer to an individual's expectations about the psychoactive effects of an addicted substance. Attributions of causality refer to an individual's pattern of beliefs that relapse to drug use as a result of internal or rather external, transient causes (e.g., allowing one to make exceptions when faced with what are judged to be unusual circumstances) finally; decision making processes are implicated in the relapse process as well. Substance use is the result of multiple decisions whose collective effects result in consumption of the intoxicant. Furthermore, alas stresses some decisions may seem inconsequential to relapse but may actually have downstream implications that place the user in a high risk situation. According to the research findings relapse cases reported in most rehabilitation centers were attributed to lack of sufficient individualized treatment, lack of adequate staff and infrastructural constraints in some centers.

Aftercare programs: Aftercare refers to the continuing treatment a person receives immediately after being discharged from residential 
rehabilitation center. Aftercare helps addicts put their newfound skills to practical use with the support of the rehabilitation centers. It is one of the most important actions any recovering addict can take to increase their odds of successful sobriety [29]. Recovery from drug addiction doesn't end once rehabilitees leave the doors of the rehabilitation center. Completing a rehabilitation treatment program is just the beginning of a long journey to maintaining sobriety. Drug rehabilitation teaches the skills needed to remain sober, but the real test comes once rehabilitees leave the program and enter the real world.

The period of time directly following rehabilitation treatment is the most fragile time for recovering addicts. This is the stage in which the rehabilitee faces the society in a different state of mind. How he / she adapts to the perception of those around him / her might determine long term abstinence from drugs or a roll back to more severe addiction spate. Treatment provides a safe and structured environment that supports a sober lifestyle, but the real world is full of temptations and triggers that threaten sobriety at every turn. Aftercare helps patients transition to 'the outside' and apply the lessons they learned in rehabilitation Centre with the support of professionals and other addicts in recovery. Other than the mandatory medical and psychological therapies in the rehab, the professionals are mandated with equipping the rehabilitees with crucial life skills. Case managers and counselors help the rehabilitees with life management issues such as living arrangements, employment, relationships, emotional healing, and continued skill building in maintaining sobriety. Peer support groups allow you to connect with other individuals just like you who can help keep you on track toward your goal of sobriety [30]. The implication is that a successful rehabilitation facility must factor an after care service program in their approach to behavior change.

Most drug addicts revert to the vice after treatment because of insufficient psychological care during and after treatment. NACADA said more emphasis should be put on psychological intervention to compliment medicine in the treatment and rehabilitation of addicts. This should recur both during regular therapy and during aftercare services. NACADA observes that treatment and rehabilitation of addicts needs a two-pronged approach with concerted efforts from the authority, the society and the addicts. "In the treatment of addicts, the pharmacological intervention and psychological care are all important. But the psychological aspect is more important because it deals with the aftermath of treatment," said NACADA treatment and rehabilitation program boss, George Murimi. Murimi said dealing with addicts needs a lot of sacrifice if they are to be helped to completely quit. So, it is important both the rehabilitators and rehabilitees to collaborate if a rehabilitation process are to be any effective. The study established that quite a number of rehabilitees were not aware of the aftercare programs or support groups.

The matrix model: This treatment approaches include drug education and self-help participation. It is a detailed treatment manual; it contains a worksheet for individual sessions, family educational groups, early recovery skills, relapse prevention conjoint sessions, urine test, 12 step programs, relapse analysis and social support groups [31]. Matrix model comprises of the treatment programs advocated in rehabilitation centers which involve interdisciplinary team to achieve set goals. In rehabilitation centers there should be individual counseling to address individual diversities, family involvement for enhancement of the recovery process, urine test for monitoring and evaluating the healing process and more so relapse prevention.
The Matrix model is a drug and substances treatment plan that gives a framework for engaging a stimulant, which abusers who are involved in treatment can use to help them achieve abstinence from such drugs [32]. Since most substance and drug abusers develop dependency on the drugs and the stimulants can assist them fight the urge. Asserts that a number of projects have demonstrated that participants treated with the matrix model demonstrate statistically significant reduction in drug and alcohol use and curbing many effects of drug and substance disorders thus improvement in psychological indicators and reduced risky sexual behaviors associated with HIV transmission. Persons with drug and substance disorder are associated with multiple problems and therefore need comprehensive intensive programs to address the problem.

The Matrix model provides a frame work for engaging stimulant abusers in treatment and helping them achieve abstinence. Rehabilitees exposed to this model learn about issues critical to addiction and relapse, thus they receive direction and support from trained personnel to become familiar with self-help programs. The program includes education for family members affected by the addiction. According observes that family education and counseling is very essential for it helps parents and significant others to accept and understand the conditions of the drug addict within the family and offer appropriate support towards recovery and minimize relapse. Family support and involvement is required in rehabilitation centers as part of the treatment programs for the family members need to be trained also on how to cope with co-dependency NACADA [10]. In conclusion matrix model is a multi-tasking program which comprises the major programs in the rehabilitation centers.

\section{Summary of literature review}

The study was based on the effectiveness of rehabilitation programs in modifying behavioral disorders exhibited by drug addicts. Rehabilitation programs entail medical and psychotherapeutic treatment. The programs include Assessment which is very crucial on determining the kind appropriate programs for specific client. It entails brief history of the client, the substance in use, any past treatment and Mental Status Examination (MSE).

Counseling ascertains whether the client is willing to undergo the therapy and identifies which part of assessment should be designed for an effective treatment program for the client. Pharmacotherapy is part of medical treatment which entails detoxification as the initial stage of drug treatment. Drug addicts are likely to experience complicated withdrawal symptoms which need to be addressed and thus detoxification alleviates some of the life threatening symptoms. Lastly the Matrix model is a multi-component framework treatment for stimulant abusers which addresses their needs systematically. It entails psycho education; relapse prevention, individual contact with therapist which enhances behavior change.

Review on Cognitive behavioral theory (CBT) reveal that processing of information is crucial for the survival of any organism, thus helping clients to correct their irrational ways of processing information in the environment. The theory is designed by Psychologists and Psychiatrists to help disturbed people to function normally as expected in the society through developing rational thinking and avoiding faulty mental process which causes them to manifest the characteristics of emotional disturbances [33].

The conceptual framework of this study, illustrated the rehabilitation programs which enhance effectiveness in assisting drug 
addicts in rehabilitation Centers. If the programs / services are adequate, well-structured and based on the client's specific needs and are identified through comprehensive assessment they may lead to high achievement in modifying personality disorders exhibited by drug addicts.

\section{Conceptual framework}

The conceptual framework of this study emanates from the correlation between competent rehabilitation practices and ideal resources with respect to effective drug rehabilitation. This is shown in Figure 1.

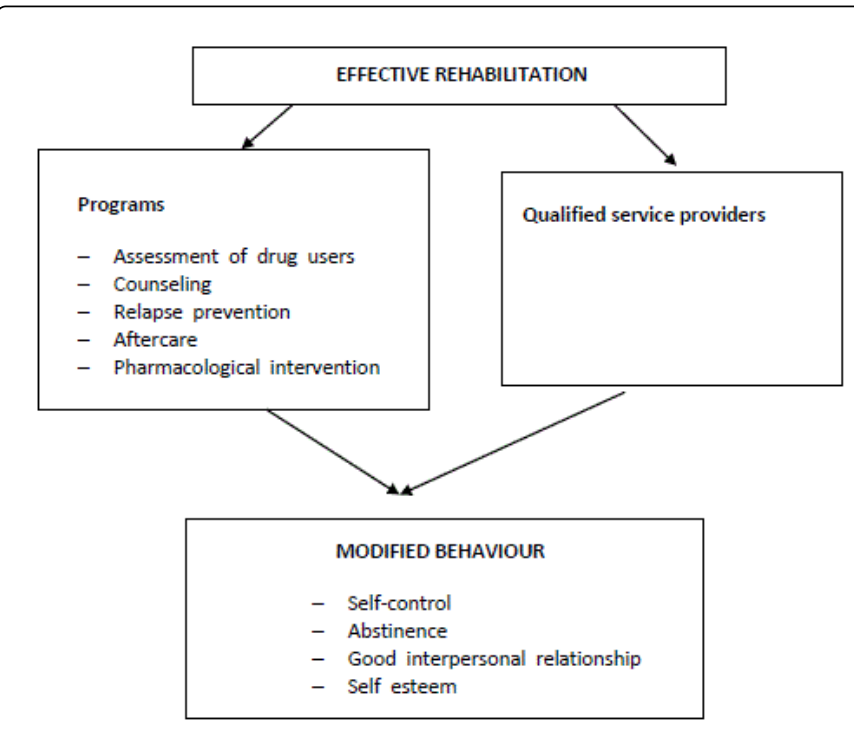

Figure 1: Conceptual Framework.

Figure 1 shows that successful drug rehabilitation is determined by the relationship of certain competent rehabilitation practices and ideal resources. Effective rehabilitation practices include adequate treatment programs, qualified service providers, efficient assessment procedures, adequate and safe infrastructural resources. An ideal interplay of these ideal resources in the rehabilitation centers ultimately results to an effective drug rehabilitation process hence modified behavior.

\section{Methodology}

\section{Introduction}

The purpose of the study was to establish the effectiveness of rehabilitation programs in relation to behavior modification of drug addicts in rehabilitation centers in Kisii County and its environs. This chapter deals with description of the methodology that was used in conducting the research on the effectiveness of drug rehabilitation centers in Kisii and its environs. The section is divided into the following subsections: research design, study location, target population, sampling technique, research instruments, pilot study, data collection procedures and data analysis technique [34].

\section{Research design}

The study was carried out using the descriptive, cross-sectional survey design. Descriptive study is concerned with conditions or relationships that exist, opinions that are held, processes that are going on, effects that are evident or trends that are developing. It is concerned with the present although it often considers past events and the influences as they relate to current conditions [35] describes crosssectional survey design as data collected at one point in time from a sample selected to represent a larger population. The design was to collect data on a sample or cross-section of the respondents who were selected to represent rehabilitees (drug addicts) and service providers (staff) at the rehabilitation centers in Kisii County.

\section{Study location}

The study was conducted in Kisii and Homabay Counties in gathering comprehensive information to meet its objective. Kisii County may not be having a wide range of rehabilitation centers manned by the government, non-governmental organizations, religious organizations but the presence of a wide variety of individuals has made the use of drugs in urban centers within the former Nyanza Province become rampant due to easy accessibility.

\section{Target population}

According to Borg target population is defined as all members of a real or hypothetical set of people, events or objects to which an investigator wishes to generalize the results of the study. This study essentially targeted rehabilitation staff members in rehabilitation centers in Kisii County as the principal respondents. Others include rehabilitees in the rehabilitation centers who were able to provide information on availability of programs in their centers. According to NACADA [10] there are a total of 61 rehabilitation and treatment centers for substance and drug addicts in Kenya. 18 of these are in Kisii County. The researcher randomly sampled a total of ten (10) out of a total of eighteen (18) rehabilitation centers and $30 \%$ of the rehabilitees in the centers in Kisii County.

\section{Sampling procedure and sample size}

The researcher was sampling in selected rehabilitation centers and purposive sampling was used to select the respondents for the study. Purposive sampling allowed the researcher to select those participants who were to provide the richest information and those who manifested the characteristics of most interest to the researcher, Best and Khan (2009). The researcher selected drug addicts undergoing rehabilitation for behavior change and also the rehabilitation centers dealing with drug addicts in Kisii County.

The study was stratified random sampling to sample the rehabilitation centers staff members. In stratified random sampling the population is first subdivided into strata, which was joined to form the complete stratified samples. The researcher used this sampling procedure because the target respondents were divided into two strata's; rehabilitees and the practitioners (service providers) at the centers. This method was supported by the assertion that if the population from which the sample is drawn does not constitute a homogenous group, then stratified sampling technique was applied to obtain a representative sample.

\section{Sample size}

Sample of the rehabilitation centers: Accordingly half or slightly above half of institutions distributed over a given geographic region is deemed a representative sample. 
Page 10 of 20

Sample of the rehabilitation respondents: According to a study $10 \%$ of the total population is held to be representative; therefore the researcher picked $10 \%$ of the total number of service providers (staff members) and $30 \%$ of the total number of rehabilitees in the selected rehabilitation centers as the respondents in the study.

\section{Description of data collection instruments}

In this study, a questionnaire and an interview Guide was used. The questionnaires were selected because they are held to be straightforward and less time consuming for both the researcher and the participants. Use of a questionnaire in this study made it possible to reach all the rehabilitation centers' staff members participating in the study since they were only required to fill in at their own time. The questionnaire consisted of both closed and open-ended items that were meant to capture the responses of the participants regarding the issues under investigation.

On the other hand, the interview method was used since it generally yields highest cooperation and lowest refusal rates, offers high response quality, takes advantage of interviewer presence and it is a multi-method data collection. An in-depth interview with the rehabilitees solicited a lot of information that was useful in determining how rehabilitation programs are effective in the behavior modification of drug addicts.

\section{Validity and reliability}

Validity is the degree to which a test measures what it purports to measure and consequently permits appropriate interpretation of the scores. To check the content validity of the instruments, the instruments were given two (2) independent experts. The views from the supervisors were also welcome. The recommended changes in the instruments were made accordingly.

Reliability is the consistency of measurement, or the degree to which an instrument measures the same subjects. Before the actual study, a pilot test of the instrument was conducted in three rehabilitation centers that were not to be part of the study sample. This was done in order to test whether: There was ambiguity in any item; if the instrument could elicit the type of data anticipated and to indicate whether the research objectives were appropriately addressed to enhance reliability and validity.

\section{Piloting}

Piloting is the pretesting of the instruments to be used to collect data. The purpose of piloting was to cross check the suitability of the questionnaire as per the study objectives, adequacy of the space provided and for clarification. Fifteen (15) staff members and 3 rehabilitees drawn from the three rehabilitation centers were requested to complete the questionnaires and responded to interview guides respectively. The staff members were randomly sampled. The participants were encouraged to make comments and suggestions concerning the instructions in the questionnaires and interview guides, clarity of the questions and relevance of the questions to ensure that the instrument measured what it was expected to measure. The pretested and revised questionnaire and interview guide were adopted for the study. Data used for piloting was utilized in the main study.

\section{Data collection procedure}

After obtaining permission from supervisors, the administrators of the selected rehabilitation centers were approached so as to explain the purpose of the study, obtain their consent and request for their assistance. Before responding to the questionnaires, the participants were given instructions on what to do. Their confidence was ensured by assuring them that their identity would not be revealed. Each respondent was expected to respond to the questionnaire items independently.

Completed questionnaires were collected immediately, where not possible, arrangements were made to pick them later. Interviews were self-administered. The researcher made early appointment with the respondents: Interviews were conducted in a quiet environment with no distraction preferably in offices. The researcher solicited the services of research assistants and ensured their competence by determining their prior experience.

\section{Data analysis procedure}

The collected data was organized and prepared for analysis by coding and entry in the Statistical Package for Social Sciences (SPSS, Ver.10). The researcher used descriptive statistics such as frequencies and percentages. The outcome of the quantitative data from the coded close-ended items was analyzed using descriptive statistics. Further, the data was interpreted and discussed in relation to the research questions. On the other hand, the qualitative data generated from open-ended questions in the interview guide was analyzed and categorized in themes in accordance with the research questions and was reported in a narrative form.

\section{Data management and ethical consideration}

The ethical considerations such as confidentiality, anonymity and avoidance of deception are very important issues in social research. Mugenda [7] asserts that a researcher has to be careful to avoid causing physical or psychological harm to respondents by asking embarrassing and irrelevant questions, threatening language or making respondents nervous. The researcher observed the above mentioned ethical considerations to avoid breach of contract and causing any physical or psychological harm to the respondents. For the purpose of this study also the researcher sought permission from persons in charge of the rehabilitation centers where the study was conducted in Kisii County and its environs within the former Nyanza province.

\section{Analysis and Presentation of the Findings}

\section{Introduction}

This chapter presents the analysis and presentation of the findings of the study on the effectiveness of drug rehabilitation programs on behavior modification of drug addicts in Kisii County and its environs. The specific objectives of the study were as follows;

To identify the types of programs offered in drug and substance rehabilitation centers in Kisii County and its environs.

To assess the capacity of service providers (staff) to offer rehabilitation services in rehabilitation centers.

To assess the effectiveness of the programmes in addressing the needs of drug addicts. 
Page 11 of 20

To describe the challenges influencing the effectiveness of rehabilitation programs.

To propose strategies to improve the effectiveness of the programs in existing rehabilitation centers in Kisii County and its environs.

The data was collected among the staff and the practitioners offering services in the rehabilitation centers and the clients admitted.

\section{Staff members and rehabilitees' response rate}

A total of 100 structured questionnaires were administered to the Staffs and additional 30 to the rehabilitees. Out of this only 86 for the staffs and 24 for the rehabilitees were retrieved back which translates to $86 \%$ and $80 \%$ response rate for staff and rehabilitees respectively. A response rate of $75 \%$ and above is deemed representative.

\section{Background characteristics of staff members and rehabilitees}

Background characteristics determined from the rehabilitation centers' staff members and rehabilitees included: gender, age, and number of years spent by staff members and the months taken by the Rehabilitees in the rehabilitation center as shown in the Table 1 and 2 below.

\begin{tabular}{|l|l|l|}
\hline Background characteristics of Staff Members & Frequency & Percent \\
\hline Gender & 49 & 56.9 \\
\hline Male & 37 & 43.1 \\
\hline Female & \multicolumn{2}{|l|}{} \\
\hline Age & 45 & \\
\hline $20-30$ Years & 26 & 52.4 \\
\hline $41-50$ Years & 11 & 30.2 \\
\hline $31-40$ Years & 4 & 12.8 \\
\hline Above 50 Years & \multicolumn{2}{|l|}{} \\
\hline Years in the Rehabilitation Center & 50 & 4.6 \\
\hline $1-5$ Years & 20 & 58.1 \\
\hline $11-15$ years & 9 & 23.2 \\
\hline $6-10$ years & 7 & 10.5 \\
\hline Above 15 years & 8.2 \\
\hline
\end{tabular}

Table 1: Background Characteristics of Staff Members.

\begin{tabular}{|l|l|l|}
\hline Background characteristics of Rehabilitees & Frequency & Percent \\
\hline Gender & 17 & 70.8 \\
\hline Male & 7 & 29.2 \\
\hline Female & & \\
\hline Age & 12 & 50.0 \\
\hline $31-40$ Years & 9 & 37.5 \\
\hline $20-30$ Years & 3 & 12.5 \\
\hline $41-50$ Years & 9 & \\
\hline
\end{tabular}

\begin{tabular}{|c|c|c|}
\hline Above 50 & - & - \\
\hline \multicolumn{3}{|c|}{ Period in the Rehabilitation Center } \\
\hline 1-3 Months & 10 & 41.7 \\
\hline 4-6 Months & 8 & 33.3 \\
\hline 7-9 Months & 6 & 25.0 \\
\hline 10 Months and above & - & - \\
\hline
\end{tabular}

Table 2: Background characteristics of Rehabilitees.

From Table 1 majority of the rehabilitation centers' staff were male, 49 (56.9\%), whereas, $37(43.1 \%)$ were female. This can be attributed to the aggressiveness of most Rehabilitees thus the call for more hiring of male staff members as opposed to female counterparts.

With regards to age, a majority of the staff members, 45 (52.4\%) were aged between 20 to 30 years; 26 (30.2\%) were between 41 and 50 years old, $11(12.8 \%)$ were between 31 and 40 years old whereas 4 (4.6\%) were above 50 years. This shows that majority of the staff members were relatively young, and were in touch with the current trends in drug rehabilitation meaning, they were able to provide accurate and reliable data on the effectiveness of drug rehabilitation centers.

Pertaining number of years as a member of staff in the rehabilitation center, a majority of the respondents, $50(58.1 \%)$ had served in their respective rehab centers for 1 to 5 years, $20(23.2 \%)$ had served for 11 to 15 years, $9(10.5 \%)$ for 6 to 10 years, whereas the rest, $7(8.2 \%)$ had served for over 15 years. This indicates that a good number of staff members had adequate experience in the drug rehabilitation to adequately address all the questions pertaining to effectiveness of drug rehabilitation centers.

From to Table 2 majority of the rehabilitees were male, 17 (70.8\%), whereas, 7 (29.2\%) were female. The study revealed that there were more male rehabilitees than female counterparts; this could be attributed by the fact that more men than women were exposed to drugs and substance abuse.

Regarding to age, a majority of the rehabilitees, 12 (50\%) were aged between 31 and 40 years; 9 (37.5\%) were between 20 to 30 years, while $3(12.5 \%)$ were between 41 and 50 years old. This shows that majority of the rehabilitees were in a period of midlife crisis characterized by daily life depressions leading them to drug and substance abuse.

With respect to period in the rehabilitation centers, a majority of the respondents, $10(41.7 \%)$ had been in their respective centers for 1 to 3 months, $8(33.3 \%)$ had been in the centers for 6 to 10 months, whereas the rest, $6(25 \%)$ had been in the relevant centers for 10 months and above. This indicates that a good number of rehabilitees had been in the rehabilitation centers for the recommended three (3) months and few stay longer due to relapse as confirmed by some staff members.

\section{Types of programs offered in drug and substance rehabilitation centers}

The study was interested in finding out the types of programs offered for both men and female rehabilitees in drug and substance rehabilitation centers in Kisii County and its environs. 
Page 12 of 20

To achieve this objective, the staff members who took part in the study were first asked to identify some specific programs that rehabilitees were taken through in their center. To which, all the staff members 86 (100\%) agreed of their existence.
The participating staff members were then provided with a list of drug rehabilitation programs, and asked how prevalent they were in their respective centers.

The responses are shown in Table 3.

\begin{tabular}{|c|c|c|c|c|c|c|c|c|c|}
\hline No. & Programs & \multicolumn{8}{|c|}{ Prevalence } \\
\hline \multirow[t]{3}{*}{ a) } & \multirow[t]{3}{*}{ Assessment of drug users } & \multicolumn{2}{|c|}{ Often } & \multicolumn{2}{|c|}{ Sometimes } & \multicolumn{2}{|c|}{ Rarely } & \multicolumn{2}{|c|}{ Never } \\
\hline & & $\mathrm{F}$ & $\%$ & $\mathrm{~F}$ & $\%$ & $\mathrm{~F}$ & $\%$ & $\mathrm{~F}$ & $\%$ \\
\hline & & 81 & 94.2 & 5 & 5.8 & - & - & - & - \\
\hline \multirow[t]{3}{*}{ b) } & Self-management and self-directed behavioral program & \multicolumn{2}{|c|}{ Yes } & \multicolumn{2}{|c|}{ Not sure } & \multicolumn{2}{|c|}{ NO } & & \\
\hline & & $\mathrm{F}$ & $\%$ & $\mathrm{~F}$ & $\%$ & $\mathrm{~F}$ & $\%$ & & \\
\hline & & 62 & 72.1 & 17 & 19.7 & 7 & 8.2 & & \\
\hline \multirow[t]{3}{*}{ c) } & Counseling & \multicolumn{2}{|c|}{ To a greater extent } & \multicolumn{2}{|c|}{ To some extent } & \multicolumn{2}{|c|}{ Not at all } & & \\
\hline & & $\mathrm{F}$ & $\%$ & $\mathrm{~F}$ & $\%$ & $\mathrm{~F}$ & $\%$ & & \\
\hline & & 79 & 91.9 & 7 & 8.1 & - & - & & \\
\hline \multirow[t]{3}{*}{ d) } & Individualized treatment plan & \multicolumn{2}{|c|}{ Agree } & \multicolumn{2}{|c|}{ Undecided } & \multicolumn{2}{|c|}{ Disagree } & & \\
\hline & & $\mathrm{F}$ & $\%$ & $\mathrm{~F}$ & $\%$ & $\mathrm{~F}$ & $\%$ & & \\
\hline & & 65 & 75.6 & 16 & 18.6 & 5 & 5.8 & & \\
\hline \multirow[t]{3}{*}{ e) } & Pharmacotherapy and medical care & \multicolumn{2}{|c|}{ Often } & \multicolumn{2}{|c|}{ Sometimes } & \multicolumn{2}{|c|}{ Rarely } & \multicolumn{2}{|c|}{ Never } \\
\hline & & $\mathrm{F}$ & $\%$ & $\mathrm{~F}$ & $\%$ & $\mathrm{~F}$ & $\%$ & $\mathrm{~F}$ & $\%$ \\
\hline & & 71 & 82.6 & 15 & 17.4 & - & - & - & - \\
\hline \multirow[t]{3}{*}{ f) } & After care and follow up programs & \multicolumn{2}{|c|}{ Yes } & \multicolumn{2}{|c|}{ Not sure } & \multicolumn{2}{|c|}{ No } & & \\
\hline & & $\mathrm{F}$ & $\%$ & $\mathrm{~F}$ & $\%$ & $\mathrm{~F}$ & $\%$ & & \\
\hline & & 56 & 65.1 & 13 & 15.1 & 7 & 19.8 & & \\
\hline
\end{tabular}

Table 3: Types of Programs Offered In Drug and Substance Rehabilitation Centers.

From the Table 3 above it was observed that an overwhelming majority of the staff members, 81 (94.2\%) indicated that assessment of drug users was often offered in their center, 7 (8.1\%) observed that the program was offered sometimes.

A majority of the staff members, $62(72.1 \%)$ observed that selfmanagement and self-directed behavioral program were offered in their centers, $17(19.7 \%)$ were not sure, whereas $7(8.2 \%)$ it was not offered.

With regards to counseling, an overwhelming majority of the staff members, 81 (94.2\%) were of the view that it was offered in their center to a greater extent; 5 (5.8\%) indicated that that it was offered to some extent.

Majority of the staff members, 65 (75.6\%) agreed that individualized treatment plan was offered in their centers, 16 (18.6\%) were undecided, whereas $5(5.8 \%)$ chose to disagree

A majority of the staff members, 71 (82.6\%) indicated that pharmacotherapy and medical care was often offered in their center, 15 (17.4\%) observed that the program was offered sometimes.

\section{Relapse prevention occurrences in the rehabilitation centers}

The staff members outlined the following as the measures in which they take to prevent relapse occurrences in their centers:

Frequent follow-ups to clients via parents and social media platforms.

Emphasizing the negative consequences of further drug use to the clients.

Reinforcing coping strategies to permanently kill the craving of drugs.

Advising the clients against engaging in situations that result to drug usage.

Advising the clients to join support groups after leaving the rehabilitation centers.

After care and Follow up programs offered in the Centre: A good number of the staff members, $56(65.1 \%)$ observed that after care and follow up programs were offered in their centers, 13 (15.1\%) were not sure, whereas 7 (19.8\%) indicated that were never offered. 
Citation: Sereta BN, Amimo FA, Ouma P, Ondimu TO (2016) An Assessment of Effectiveness of Drug Rehabilitation Programs in Kisii CountyKenya. J Health Edu Res Dev 4: 165. doi:10.4172/2380-5439.1000165

Page 13 of 20

Assessment of Rehabilitation programs in the rehabilitation centers: To assess the effectiveness of the programs offered in rehab centers procedures on offering treatment to clients upon admission were given as recommended by NACADA 2011 National standards for treatment and rehabilitation of persons with substance use disorders. The table below shows the assessment procedures.
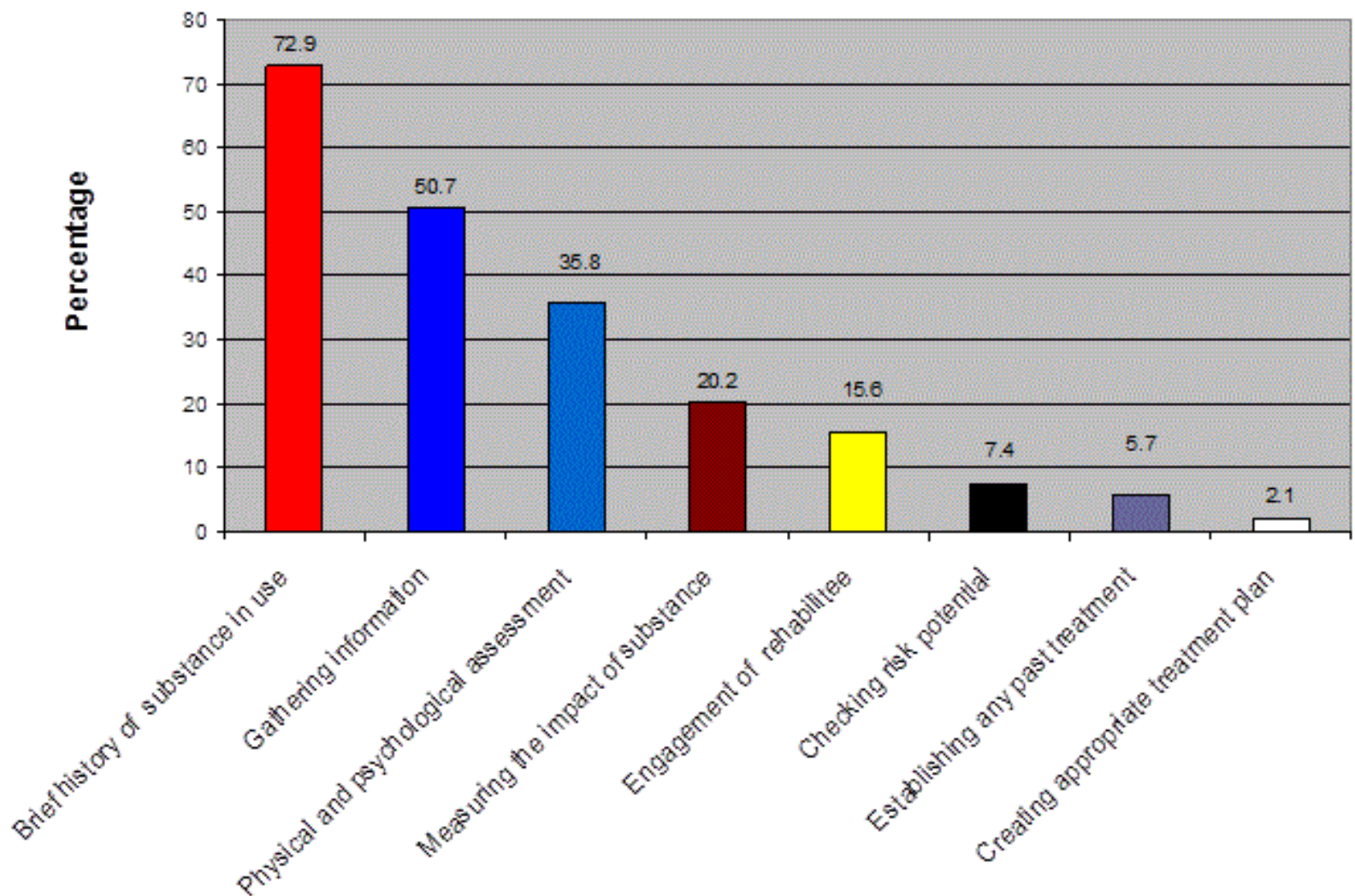

Procedures

Figure 2: Procedure of rehabilitee assessment in the rehabilitation centers.

Figure 2 shows that a majority of the staff members (72.9\%) pointed out that the main procedure of rehabilitee assessment in the rehabilitation centers was determining a brief history of the substance in use; $50.7 \%$ indicated gathering information about the situation causing the problem; $35.8 \%$ pointed out assessing the physical and psychological functioning of the client; $20.2 \%$ measuring the impact substance abuse has had on the individual; $15.6 \%$ engagement between the rehabilitee and the counselor; $7.4 \%$ checking risk potential, for instance, suicidal attempts; $5.7 \%$ establishing any past treatment; and $2.1 \%$ coming up with appropriate treatment plan to address the actual problem of rehabilitees. The study established that proper procedures were followed in preparing treatment plans for individual clients making the program more effective.

To ascertain this, the rehabilitees were also asked to outline some of the procedures they were taken through while in the rehab centre which were given as follows;

Check for drug possession

Status Mental Examination (SME)

Medical tests

Detoxification

\section{Spiritual and psychological counseling}

\section{Capacity of service providers (staff) to offer rehabilitation services in rehabilitation centers}

The study also sought to determine the capacity of service providers (staff) to offer rehabilitation services in rehabilitation centers. To attain this objective, the staff members were first asked to indicate their current position in the rehabilitation center, highest educational and professional training, how long the training took, institution of the training, components of drug management that the course entailed.

Current position of staff members in the rehabilitation centers: Table 4 shows distribution of staff members in the study in accordance to their various positions in the respective rehabilitation centers.

According to Table 4 a good number of the staff members who took part in the study, $38(44.2 \%)$ were occupational therapists, $21(24.4 \%)$ were occupational and intern counselors, 11 (12.8\%) were psychologists, $9(10.5 \%)$ were physiotherapists, 5 (5.8\%) were clinical services managers, and $2(2.3 \%)$ were social workers. 
Citation: Sereta BN, Amimo FA, Ouma P, Ondimu TO (2016) An Assessment of Effectiveness of Drug Rehabilitation Programs in Kisii CountyKenya. J Health Edu Res Dev 4: 165. doi:10.4172/2380-5439.1000165

Page 14 of 20

Highest educational and professional training of staff members: Table 5 shows distribution of staff members in the study in regards to their educational and professional training.

\begin{tabular}{|l|l|l|}
\hline Position & Frequency & Percent \\
\hline Occupational Therapists & 38 & 44.2 \\
\hline Counselors (Occupational and Intern) & 21 & 24.4 \\
\hline Psychologists & 11 & 12.8 \\
\hline Physiotherapists & 9 & 10.5 \\
\hline Clinical Services Managers & 5 & 5.8 \\
\hline Social Workers & 2 & 2.3 \\
\hline
\end{tabular}

Table 4: Position of staff members in the rehab centers.

\begin{tabular}{|l|l|l|}
\hline Educational and professional training & Frequency & Percent \\
\hline Bachelor degree in occupational therapy & 50 & 58.1 \\
\hline Masters of Arts in Counseling & 19 & 22.1 \\
\hline MSc in Applied Psychology & 9 & 10.5 \\
\hline Diploma in chemical dependency counseling & 8 & 9.3 \\
\hline
\end{tabular}

Table 5: Highest educational and professional training.

Table 5 shows that a majority of the staff members, 86 (61.4\%) had a bachelor degree in occupational therapy, 22 (15.7\%) had a Masters of Arts in Counseling, 20 (14.3\%) had a Master of Science in Applied Psychology, whereas the rest, $12(8.6 \%)$ had a diploma in chemical dependency counseling. According to the study it was observed that most of the staff members were qualified.

Length the training took: Figure 3 shows the period that the staff members' educational and professional training.

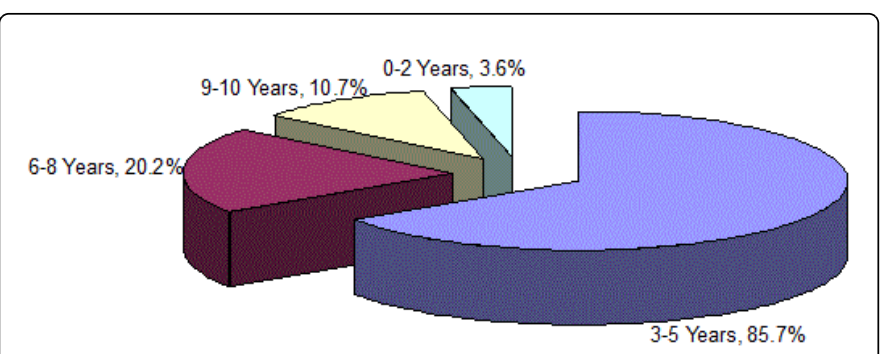

Figure 3: Length of training.

According to Figure 4, a majority of the staff members (85.7\%) had trained for 3 to 5 years, $20.2 \%$ had trained for 6 to 8 years. Those who had trained for 9 to 10 years and 0 to 2 years were presented by $10.7 \%$ and $3.6 \%$ respectively.

Where staff members undertook the training: Table 6 shows the various institutions where staff members in the study undertook their training.

According to Table 6 a good number of the staff members in the study, 36 (41.9\%) undertook their training in the University of Nairobi, 23 (26.7\%) attended Kenyatta University, 10 (11.6\%) trained at Support for Addictions Prevention and Treatment in Africa (SAPTA), whereas 7 (19.8\%) undertook their training at the Presbyterian University of East Africa.

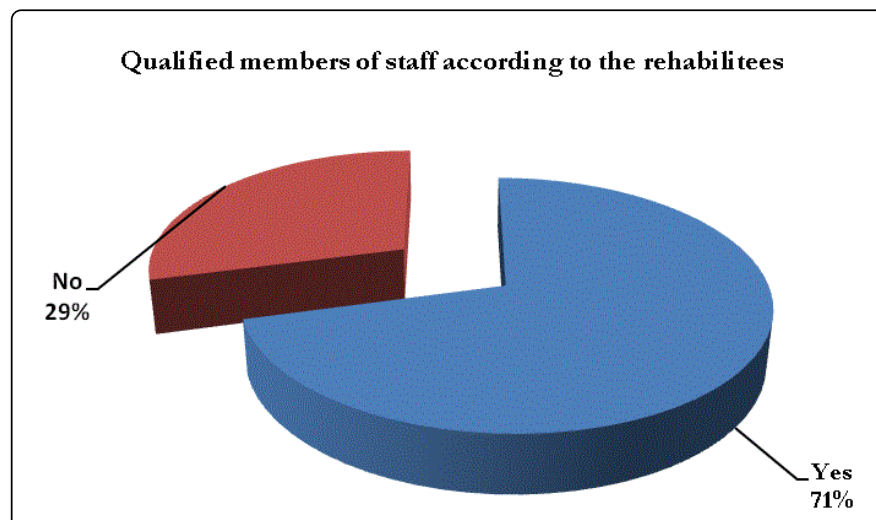

Figure 4: Whether staff members were qualified enough.

\begin{tabular}{|l|l|l|}
\hline Institutions & F & $\%$ \\
\hline University of Nairobi & 36 & 41.9 \\
\hline Kenyatta University & 23 & 26.7 \\
\hline $\begin{array}{l}\text { Support for Addictions Prevention and } \\
\text { Treatment in Africa (SAPTA) }\end{array}$ & 10 & 11.6 \\
\hline Presbyterian University of East Africa & 7 & 19.8 \\
\hline
\end{tabular}

Table 6: Where staff members undertook the training.

Components of drug management in their training: The following are some of the key components of drug management entailed in courses undertaken by the staff members in the study:

Pharmacology

Medication therapy review (MTR)

Personal medication record (PMR)

Medication-related action plan (MAP)

Drug intervention and/or referral

Drug documentation and follow-up

Relapse prevention

12-step recovery process

Tasks staff members carry out in the rehab: Figure 5 shows the tasks staff members carry out in their respective rehab centers.

According to Figure 5 a majority of staff members (89.2\%) indicated assessment was carried out, $73.2 \%$ conducted pharmacotherapy, $55.3 \%$ group counseling, $44.6 \%$ individual counseling, and $17.9 \%$ family therapy.

Capacity to handle key rehabilitation tasks: The staff members were asked to indicate their level of capacity to handle the following rehabilitation programs: Assessment; group counseling; individual counseling; family therapy; pharmacotherapy. Table 7 shows their response. 
Citation: Sereta BN, Amimo FA, Ouma P, Ondimu TO (2016) An Assessment of Effectiveness of Drug Rehabilitation Programs in Kisii County-

Table 7 shows that a great majority of staff members in the study $132(94.2 \%)$ were very prepared to handle the key rehabilitation tasks. The remainder, 8 (5.8\%) were somewhat prepared.

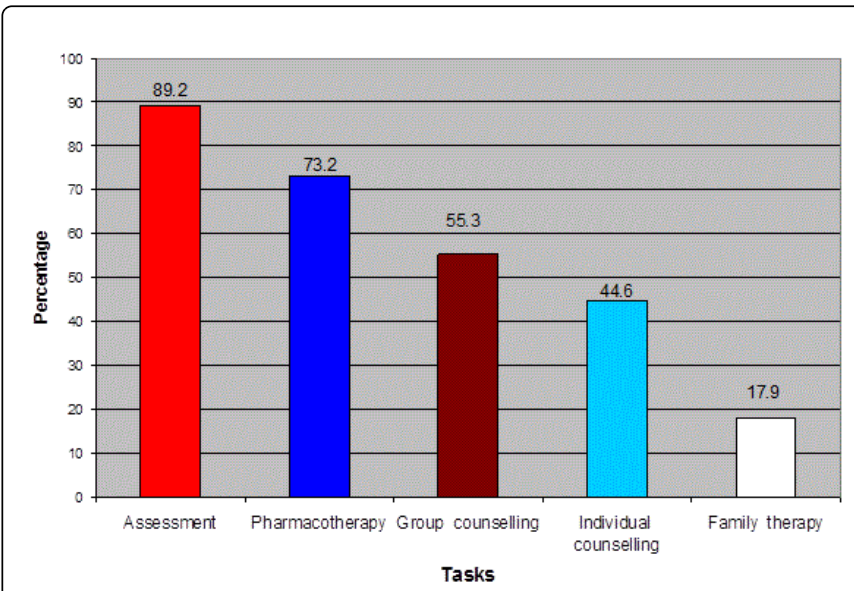

Figure 5: Tasks carried out by staff members.

\begin{tabular}{|l|l|l|}
\hline Capacity & Frequency & Percent \\
\hline Very prepared & 53 & 61.6 \\
\hline Somewhat prepared & 33 & 38.4 \\
\hline Not prepared & - & - \\
\hline
\end{tabular}

Table 7: Capacity of staff members to handle key rehabilitation tasks.

Rehabilitees' response on capacity of service providers (staff) to offer rehabilitation services in rehabilitation centers: To attain this, the rehabilitees were asked whether they felt that the staff members in the rehabilitation centers were qualified enough to take them through the rehabilitation procedures. Figure 4 shows their response.

Figure 4 shows $71 \%$ of the rehabilitees in the study indicated that the staff members in the rehabilitation centers were qualified enough to take them through the rehab procedures, $29 \%$ observed that the staff members were not qualified.

Clearly it can now be ascertained that majority of the staff members were qualified to offer services in the rehab centers.

Staff Members' Response on type of continuing / after care services available in the rehabilitation centers: The staff members participating in the study were first asked whether there were continuing/after care services available in the rehabilitation centers. Their response is shown on Figures 6 and 7.

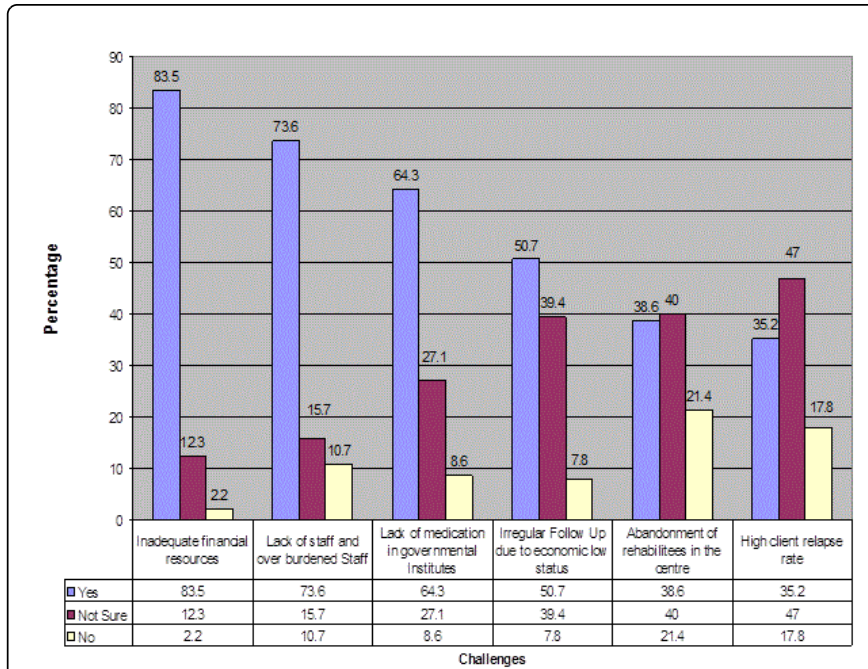

Figure 6: Challenges Facing Rehabilitation Centers.

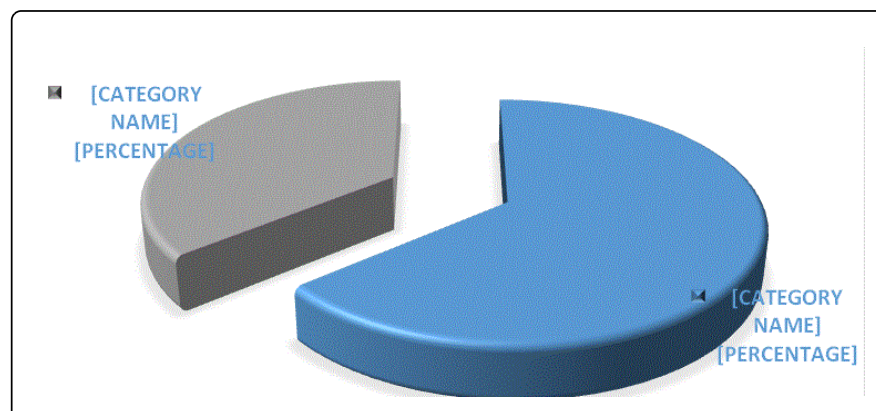

Figure 7: Whether there were continuing/after care services in the rehabilitation centers.

According to Figure 7, a great majority of the staff members in the study (64\%) pointed out that there were no continuing/after care services available in their respective rehabilitation centers. The remainder $(36 \%)$ indicated that there were continuing / after care services. This lack of continuing/after care services could be caused by lack of, or ineffective support groups

The staff members were then provided with a number of continuing / after care services in the rehabilitation centers, and asked to indicate to what extent they were prevalent in their centers. Table 8 shows their response.

\begin{tabular}{|l|}
\hline Services \\
\hline Psychological intervention to compliment medicine in the treatment of rehabilitees \\
\hline Continued skill building of rehabilitees in maintaining sobriety \\
\hline
\end{tabular}

\begin{tabular}{|l|l|l|l|l|l|}
\hline \multicolumn{2}{|l|}{ To a greater extent } & \multicolumn{2}{l|}{ To some extent } & \multicolumn{2}{l|}{ Not at all } \\
\hline F & $\%$ & F & $\%$ & F & $\%$ \\
\hline 81 & 95.3 & 5 & 5.8 & - & - \\
\hline 62 & 72.1 & 17 & 19.8 & 7 & 8.2 \\
\hline
\end{tabular}


Citation: Sereta BN, Amimo FA, Ouma P, Ondimu TO (2016) An Assessment of Effectiveness of Drug Rehabilitation Programs in Kisii County-

Page 16 of 20

Helping rehabilitees with life management issues such as living arrangements, employment, relationships

Table 8: Continuing / after care services in the rehabilitation centers.

Table shows staff members' response on the extent to which continuing/after care services existed in the rehab centers.

With regards to psychological intervention to compliment medicine in the treatment of rehabilitees, $81(95.3 \%)$ indicted that it existed in centers to a greater extent, while $5(5.8 \%)$ observed that it did, to some extent.

Pertaining to continued skill building of rehabilitees in maintaining sobriety, a majority of the staff members, $62(72.1 \%)$ observed that it existed in centers, to a greater extent, 17 (19.8\%) indicated that it did, to some extent, whilst 7 (8.2\%) indicated that it did not exist at all.
Regarding helping rehabilitees with life management issues such as living arrangements, employment, relationships, 40 (46.5\%) affirmed that the service existed in centers to a greater extent, 25 (29.1\%) were of the opinion that it did, to some extent, while 21 (24.4\%) observed that it did not exist at all. The study established some of the reformed rehabilitees were absorbed in the rehab centers as staff members.

The staff members were further asked to point out ways in which the continuing/after care services available in their center were effective. Figure 8 shows their response.

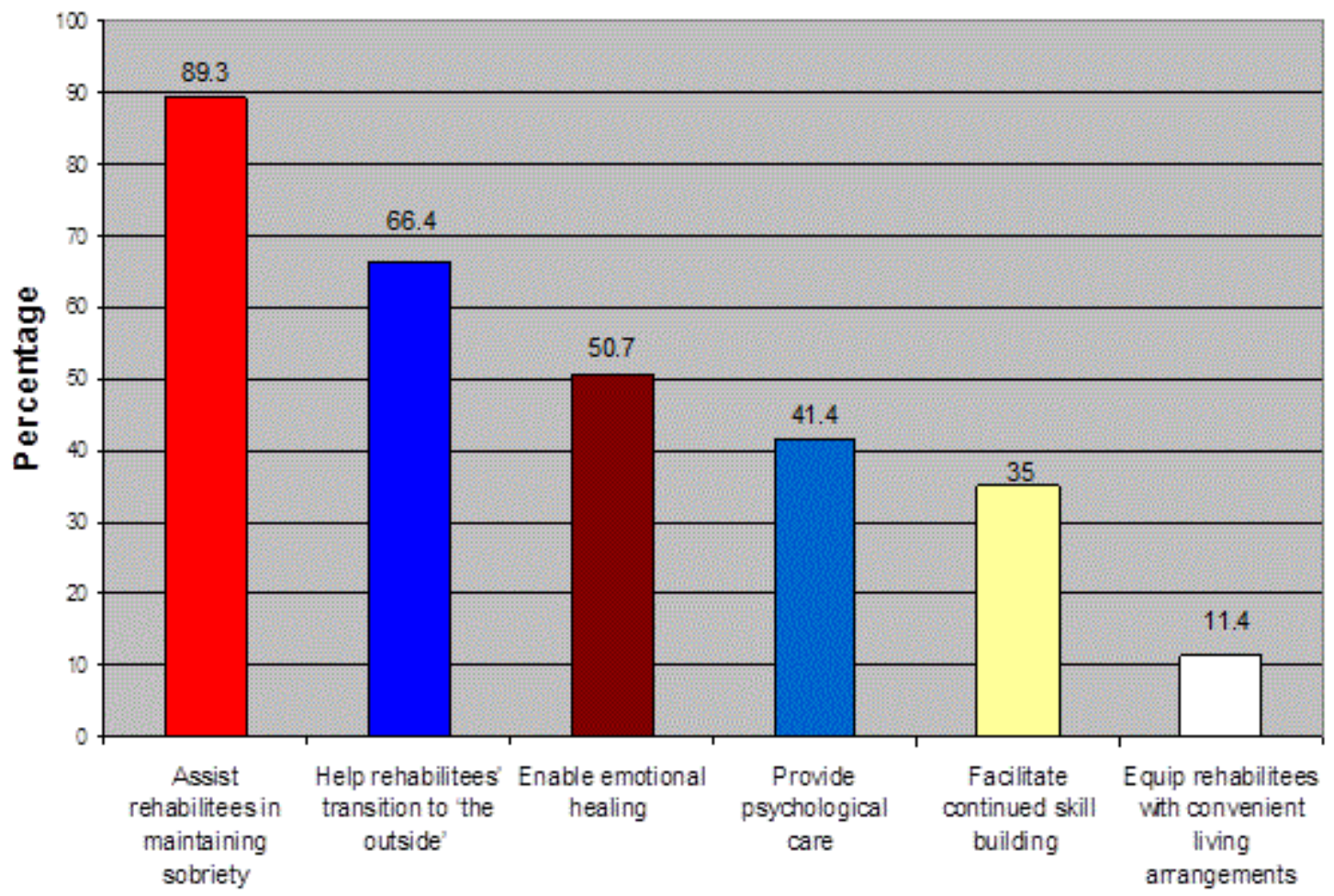

Effectiveness

Figure 8: Effectiveness of the continuing / after care services.

Figure 8 shows that a majority of the staff members (89.3\%) observed that the main effectiveness of the continuing/after care services was that they assisted rehabilitees in maintaining sobriety; $66.4 \%$ pointed out that the services helped rehabilitees' transition to 'the outside world' and apply the lessons they learned in rehabilitation center; $50.7 \%$ indicated the services enabled emotional healing among rehabilitees; $41.4 \%$ observed that the services provide psychological care during and after treatment; 35\%\% indicated that the services facilitated continued skill building among rehabilitees; and $11.4 \%$ outlined that the services equip rehabilitees with convenient living arrangements.

\section{Challenges facing rehabilitation centers}

To attain this objective, the staff members participating in the study were asked whether there were challenges encountered in their various rehabilitation centers. To which all the staff members $86(100 \%)$ indicated that there were challenges 
The staff members were then provided with a number of perceived challenges facing rehabilitation centers, and asked to indicate whether they were prevalent in their centers, not prevalent, or they were not sure if they were prevalent or not. Figure 4 shows their response.

Figure 6 shows the response of the staff members on the challenges facing rehabilitation centers.

Pertaining to inadequate financial resources to keep the rehabilitation programs running, a majority of the participating staff members $(83.5 \%)$ pointed out that it was a challenge, $12.3 \%$ observed that they were not sure, $2.2 \%$ indicated that it was not a challenge.

With regards to lack of staff and overburdened staff, a majority of the staff members $(73.6 \%)$ indicated that it was a challenge, $15.7 \%$ observed that they were not sure, $8.6 \%$ indicated that it was not a challenge in their centers.

Concerning lack of medication in governmental institutes, $64.3 \%$ of the staff members observed that it was a challenge, $27.1 \%$ observed that they were not sure, $8.6 \%$ indicated that it was not a challenge in their centers.

Regarding, irregular follow up due to economic low status, 50.7\% pointed out that it was a challenge, $40 \%$ observed that they were not sure, $21.4 \%$ indicated that it was not a challenge.

With respect to abandonment of rehabilitees in the center by relatives to get rid of them, $38.6 \%$ indicated that it was a challenge, $47 \%$ observed that they were not sure, $17.8 \%$ indicated that it was not a challenge in their centers

On high client relapse rate, $35.2 \%$ indicated that it was a challenge, $47 \%$ observed that they were not sure, $17.8 \%$ indicated that it was not a challenge in their centers.

Rehabilitees' response on challenges facing rehabilitation centers: The rehabilitees observed the following as the challenges facing rehabilitation centers

Lack of withdrawal reinforcing drugs

Untrustworthy rehabilitation center staff members

Ignorance of patients by management and staff members due to lack of rapport

Lack of recreation facilities leading to boredom

Limited or no communication of rehabilitees and their family

Congestion of rehabilitation centers putting the rehabilitees at a risk of contracting communicable diseases

Hostility and paranoia among the rehabilitees due to combination of patience with mild and severe cases.

\section{Improving the effectiveness of the existing rehabilitation centers}

The study also sought to establish the ways of improving the effectiveness of the existing rehabilitation centers.

Staff members' response on improving the effectiveness of the existing rehabilitation centers: Staff members in the study were asked to outline ways in which challenges encountered in rehabilitation centers can be countered. They pointed out following as the main ways:
Funding by the government to facilitate better services to all rehabilitation centers, private and public

Emphasis on individualized treatment plan instead of group therapy

Employment of more staff members to cater to all clients

Continuous follow ups by the rehab staff and management

Additional recreation activities in the rehabilitation program to avoid boredom

Enhanced interaction between the staff, the rehabilitees, and family members

Emphasis on observance of ethical issues especially those pertaining to confidentiality

Rehabilitees' response on improving the effectiveness of the existing rehabilitation centers: The rehabilitees reported the following as the key ways to improve the effectiveness of the existing rehabilitation centers:

\section{Reducing rehabilitation expenses}

More recreational facilities and activities

More qualified staff to practice confidentiality

Seeking opinions from patients. This can be done through individualized counseling

Granting a little more freedom to the patients

Focus on individual treatment which includes significant others or other family members

Incorporation of former addicts in offering services in the rehabilitation center to act as mentors.

\section{Summary of research findings}

The researcher sought to identifying the types of programs offered in drug and substance rehabilitation centers in Kisii County, the study revealed that the main type of program offered in drug and substance rehabilitation centers in Kisii County to be assessment of drug users (94.2\%) which was mainly done through determining a brief history of the substance in use (72.9\%), Mental Status Examination (MSE), types of abused drug, length of use and gathering information about the situation causing the drug problem (50.7\%). The other key programs offered were counseling (91.9\%); detoxification; and pharmacotherapy and medical care $(82.6 \%)$ and relapse prevention.

The researcher sought to find out whether the service providers had the capacity to offer the rehabilitation services in the rehabilitation centers which were based on their professional qualifications. The study revealed that Most of the service providers (staff) in the study were occupational therapists $(44.2 \%)$, both occupational and intern counselors (24.4\%), and psychologists (12.8\%). Majority of them had a bachelor degree in occupational therapy (58.1\%) and had trained for 3 to 5 years $(85.7 \%)$ mainly at the University of Nairobi $(41.9 \%)$ and Kenyatta University (26.7\%). Key components of drug management in their training included: Pharmacology; Medication therapy review (MTR); Personal medication record (PMR); and Medication-related action plan (MAP). The key tasks that these qualifications enabled the service providers to execute were mainly: assessment (89.2\%); pharmacotherapy (73.2\%); and group counselling (55.3\%)- with majority of the service providers $(61.6 \%)$ observing that they were very prepared to handle these key rehabilitation tasks. Therefore the study 
Page 18 of 20

established that majority of para-professional which include the counsellors, social workers and clinical officers were trained and qualified. However, half of the rehabilitees (50\%) observed that the staff members were not qualified citing that the staff members were dishonest, reluctant, and rude, which created tension in rapport establishment among the service providers and the rehabilitees.

The researcher wanted to establish the type and quality of continuing/after care services available in the rehabilitation centers, the study revealed that Continuing/after care services were available in a great majority of rehabilitation centers (91.4\%). These services were available mainly in terms of psychological intervention to compliment medicine in the treatment of rehabilitees (95.3\%) and continued skill building of rehabilitees in maintaining sobriety (72.1\%). Effectiveness of the continuing/after care services manifested itself through assisting rehabilitees in maintaining sobriety (89.3\%), helping rehabilitees' transition to 'the outside' and apply the lessons they learned in rehabilitation center (66.4\%), and enabling emotional healing among rehabilitees $(50.7 \%)$. The study revealed that most of the continuing follow ups were done in form of appointments given after discharge.

The researcher sought to find out the challenges influencing the effectiveness of rehabilitation programs, the research revealed that majority of the rehabilitation centers experienced/faced inadequate financial resources (83.5\%), lack of staff and overburdened staff (73.6\%), lack of medication in governmental institutes (64.3\%), and irregular follow up due to economic low status $(50.7 \%)$ were the prime challenges facing rehabilitation centers according to the staff members. Rehabilitees observed: Lack of recreation facilities leading to boredom; lack of withdrawal reinforcing drugs; congestion of rehabilitation centers; and hostility and paranoia among the rehabilitees due to combination of patience with mild and severe cases. Most of the rehabilitation centers were faced with financial crises contributing to unemployment of adequate staff and provision of some infrastructural resources needed in the rehabilitation centers.

The researcher sought to find out what needs to be done to improve the effectiveness of the programs in existing rehabilitation centers, the study revealed that staff members observed that challenges can be solved mainly through: Funding by the government to facilitate better services; especially individualized treatment plan instead of group therapy; employment of more staff members to cater to all clients; and continuous follow ups by the rehab staff and management. The rehabilitees outlined the following as the key resolutions: Reducing rehabilitation expenses; more recreational facilities and activities; and more qualified staff who can observe ethical issues as pertains to confidentiality.

\section{Findings, Conclusions and Recommendation of the Study}

\section{Introduction}

This chapter presents a summary of the research findings gathered from the analysis of the data as per the specific objectives of the study, conclusion and recommendations on the possible ways of addressing challenges facing rehabilitation programs in various rehabilitation centers in Kisii County.

\section{Summary of the findings}

The overall purpose of the study was to find out the effectiveness of drug rehabilitation programs on behavior modification on drug abuse in Kisii County and its environs, document challenges faced by various rehabilitation centers and come up with various proposals on how the challenges faced can be improved. The specific objectives of the study were;

To identify the types of programs offered in drug and rehabilitation centers.

To assess the effectiveness of the programs in addressing the needs of drug addicts based on the procedures followed in admission of the clients,

To assess the capacity/qualifications of the staff members,

To document how challenges facing the effectiveness of rehabilitation program,

To establish what can be done to improve the effectiveness by addressing the challenges faced.

Types of programs offered in rehab centres: Drug rehabilitation (often drug rehab or just rehab) is a term for the processes of medical or psychotherapeutic treatment, for dependency on psychoactive substances such as alcohol, prescription drugs, and street drugs such as cocaine, heroin or amphamines. The general intent is to enable the patient to cease substance abuse, in order to avoid the psychological, legal, financial, social, and physical consequences that can be caused, especially by extreme abuse. Treatment includes medication for depression or other disorders, counseling by experts and sharing of experience with other addicts. Some rehab centers include meditation and spiritual wisdom in the treatment process.

The study is hinged on cognitive behavioral therapy by Aaron Becks approach; it emphasizes teaching clients' self-management skills and how to restructure their thoughts. The clients learn to use these techniques to control their lives to deal effectively with present and future problems and function well without ongoing therapy. From the current study it was observed a number of rehabilitation programs for drug and alcohol addiction were offered which included: Assessment of drug users which entails brief history of the substance in use, any past treatment and mental status examination, counseling, individualized treatment plan, pharmacotherapy and medical care which deals with physiological effects of drugs and relapse prevention techniques thus helping the rehabilitees to remain sober even after being discharged from the rehabilitation centers. It's worth noting that most researches have rarely mentioned the aspect of meditation as a program being offered, may be this is based on priority set by the researchers themselves including the current study.

Assessing treatment needs: While each individual in treatment will have specific long- and short-term goals, all

Specialized substance abuse treatment programs have three similar generalized goals

Reducing substance abuse or achieving a substance-free life

Maximizing multiple aspects of life functioning

Preventing or reducing the frequency and severity of relapse

For most patients, the primary goal of treatment is attainment and maintenance of abstinence (with the exception of methadonemaintained patients), but this may take numerous attempts and 
failures at "controlled" use before sufficient motivation is mobilized. Until the patient accepts that abstinence is necessary. This has an aim of convincing the patient of her individual responsibility for becoming abstinent. Total abstinence is strongly associated with a positive longterm prognosis. The current study established that assessment was done in most of rehab centers at $89.2 \%$ in Kisii County and its environs followed by Pharmacotherapy at $73.2 \%$. This was done to formulate treatment goals and implement appropriate treatment plans to address individual needs. Much of the findings in the current study under assessment of effectiveness of programs offered in rehab centers in addressing individual's needs, concurred with previous findings done by other researchers.

Quality / capacity of staff in rehabilitation centre: Substance abuse treatment is delivered in two basic settings or environments: inpatient and outpatient. Although the two types of settings vary widely by cost, recent evaluation studies have not found that treatment setting correlates strongly with a successful outcome. In fact, research has not found a clear relationship between treatment setting and the amounts or types of services offered, although there is a correlation between the services provided and post-treatment outcomes. The current study has that the established vast majority of those in charge of helping the rehabilitees to recuperate from drug and substance abuse is of high qualification. From other researches done previously it was established that most staffs have a minimum qualification of Diploma as required by NACADA.

Challenges faced in most rehabilitation centers: Readers may not be aware of the sheer scale of spending on services providing rehabilitation and recovery. A report commissioned by the Department of Health documented health and social care spending on

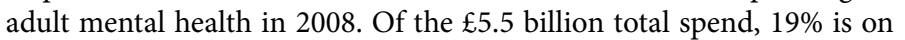
continuing hospital care, residential and housing care and home support services that are of direct relevance to rehabilitation services in short financial aspect has posed a lot of challenges to the effectiveness of this rehabilitation centers.

Most drug addicts feel wounded neglected and need love, empathy and conducive or less threatening environment in order to respond positively to the therapeutic processes. This implies that physical environment is very important in enhancing behavior change among the drug addicts. The current study found out that apart from financial constraints the rehab centers are exposed to, congestion, inadequate recreational facilities and poor infrastructure among others were very much felt by both staff and the rehabilitees themselves leading to some of the rehabilitees ending up withdrawing from the rehab without completing their prescribed treatment.

Improvement on effectiveness of the rehabs: For effectiveness of rehabs to be realized a solution has to be provided for the aforementioned challenges. The most notorious one is financial constraint. In times of increasing constraints on resources it is imperative for local mental health economies that this money available is spent effectively. 'Repatriating' people to local services and helping them live as independently as possible is likely to benefit the individual as well as saving money which could be used in more useful ways.

\section{Conclusions}

The conclusions of the study were derived from the major findings and were based on the specific research objectives; most of the rehabilitation centers offered recommended programs by National Standards of Treatment, and assessment emerged as the program offered in rehabilitation centers., which was found to be vital in identifying the client's state of functioning. Staff members in rehabilitation centers in Kisii County and its environs are sufficiently trained, with a good number of them holding degrees, diplomas and certificates from reputable institutions. They also possess proficiency in drug management and rehabilitation tasks. Most of the rehabilitation centers offer continuing/after care services to their clients using psychological interventions, and personal empowerment of the rehabilitees. Financial impediments like insufficient staff, medication and facilities as well as inconsistent follow ups are the major challenges facing rehabilitation centers in Kisii County and its environs. These challenges can only be curbed by sufficient funding of these institutions to enable employment of adequate staff and acquisition of better infrastructure to enable enhanced individual attention to rehabilitees.

\section{Recommendations}

Based upon the research findings on effectiveness of rehabilitation programs on behavior modification in Kisii County and its environs, various recommendations are proposed to enhance the effectiveness of the existing rehabilitation programs.

Rehabilitation management should recruit clients in references of the infrastructures in the rehabilitation centers to avoid congestion and the strained resources observed in rehabilitation centers during the study. The ratios among the client and service providers should also be considered to enhance individualized treatment rather than group therapy.

The study recommends the policy makers and other stakeholders to formulate ways of funding the existing rehabilitation centers whether government or private owned to reduce the current cost. Most of the rehabilitation centers are privately owned and exorbitantly expensive. Only the better off in the society can afford thus locking out many people who require rehabilitation services. The clients depart the rehabilitation centers before full recovery due to the cost implication.

The policy makers need to establish ways of promoting support groups to enhance after care services once the clients are discharged from the rehabilitation centers.

Structured after care programs can help maintain sobriety of the client after discharge. The study recommends the government should establish fully sponsored rehabilitation centre, and expand and renovate the existing rehabilitation centers to accommodate the growing number of drug and substance addicts who need to be rehabilitated.

The government should deploy more staff in the rehabilitation centers and fund construction of recreation facilities to avoid boredom expressed by many rehabilitees.

The study recommends refresher courses or workshops for service provided to reduce burn-out due to handling high numbers of clients and keep them informed of safeguarding service delivery in the rehabilitation.

\section{Areas for further research}

The study recommends that: Further research can be done on how rehabilitation center's infrastructure influence on the recovery of rehabilitees 
Further research can also be conducted on contribution of support groups in maintaining sobriety of rehabilitees after being discharged from rehabilitation centres.

\section{Acknowledgements}

I thank God the almighty whose blessings and grace have been with me as I undertook this course. I thank my immediate family for their moral and financial support, encouragement and understanding.

I wish to convey sincere gratitude to my supervisors for their guidance, suggestions and constructive criticisms towards the successful writing of this work.

Special thanks go to all the friends who in a small or big way contributed towards the successful writing of this thesis.

\section{References}

1. World Drug Report (2007) UNODC.

2. Hubbard RL, Craddock SG, Flynn PM, Anderson J, Etheridge RM (1998) Overview of 1-year follow-up outcomes in the Drug Abuse Treatment Outcome Study (DATOS). Psychology of Addictive Behaviors 11: 291-298.

3. Benjamin KR (2003) Control of landmark events in meiosis by the CDK Cdc28 and the meiosis-specific kinase Ime2. Genes Dev 17: 1524-1539.

4. Bruner (2008) Learning Theory in Education. Simply Psychology.

5. Sacks S, Banks S, Mc Kendrick K, Sacks JY (2008) Modified therapeutic community for co-occurring disorders: A summary of four studies. J Subst Abuse Treat 34: 112-122.

6. World Drug Report (2009) UNODC.

7. Mugenda O, Mugenda G (2003) Research methods, quantitative and qualitative Approaches. Acts press, Nairobi.

8. Rhodes T, Singer M (1998) The social structural production of HIV risk among injecting drug users. Social Science \& Medicine pp: 1-19.

9. Suzanne M, Jessie MK, Nora HM, PsyD GKP, Jacquelyn CC, et al. (2002) HIV-Positive Women Report More Lifetime Partner Violence: Findings From a Voluntary Counseling and Testing Clinic in Dar es Salaam, Tanzania. American Journal of Public Health 92: 1-8.

10. World Drug Report (2004) UNODC.

11. Nathaniel-James DA, Frith CD (2002) The role of the dorsolateral prefrontal cortex: evidence from the effects of contextual constraint in a sentence completion task. Neuroimage 16: 1094-1102.

12. Poulin C, Elliott D (1997) Alcohol, tobacco and cannabis use among Nova Scotia adolescents: implications for prevention and harm reduction. CMAJ 156: 1387-1393.

13. Hibbel B, Anderson B, Bjarnason T, Kokkeri A, Morgan M, et al. (1995) Alcohol and other drug use among medical students in 26 European countries. The European schools project on alcohol and other drugs (ESPAD) study, Stockholm, Council of Europe.

14. Raymond GM (2008) Behavior Modification: Principles and Procedures. (5th Edn) Cengage learning.
15. Higgins JP, Thompson SG, Deeks JJ, Altman DG (2003) Measuring inconsistency in meta-analyses. BMJ 327: 557-560.

16. Fatoye FO, Morakinyo O (2002) Substance use amongst secondary school students in rural and urban communities in south western Nigeria. East Afr Med J 79: 299-305.

17. Leslie C, Eskin E, Noble WS (2002) The Spectrum Kernel: A String Kernel For Svm Protein Classification. Pacific Symposium on Biocomputing 7: 566-575.

18. Kendel B, Yamaguchi K (1985) Developmental patterns of the use of legal, illegal and medically prescribed psychotropic drugs from adolescence to young adulthood. In: Jones CL, Battes RJ (Eds) Etiology of drug abuse: Implications for prevention, DHHS.

19. NACADA (2004) Building Bridges: Advisors as Architects for the Future.

20. Mpabulungi L, Muula AS (2004) Tobacco use among high shool students in Kampala, Uganda: questionnaire study. Croat Med J 45: 80-83.

21. Siringi S, Waihenya K (2001) Drug abuse rife as government braces for narcotics war in Kenyan schools.

22. Kwamanga DH, Odhiambo JA, Amukoye EI (2003) Prevalence and risk factors of smoking among secondary school students in Nairobi. East Afr Med J 80: 207-212.

23. Kanyesigye K, Basiraha R, Ampaire A, Wabwire G, Muchura S, et al. (1997) Prevalence of smoking among medical students of Makerere University, Kampala, Uganda. Tobacco: The Growing Epidemic pp: 924-926.

24. http://africacheck.org/reports/flawed-survey-claims-a-third-of-southafricans-are-drug-users/

25. Orodho J (2005) Techniques of writing research proposals and Reports in education and Social Sciences. Masola Publishers, Nairobi.

26. Mgendi C (1998) Corruption and drugs in Kenya. Africa Recovery 12: 19.

27. Lukwiya M (2000) Cigarette smoking among secondary school students in Jinja District. Proceedings of the 9th UNACOH Annual Scientific Conference, Kampala.

28. Bratter E, Kolodny C, Deep C (1984) Surviving Your Adolescence. Boston: Little Brown.

29. Siringi S (2003) Kenya: Alarm Over Drugs: Nacada Study Cites Rampant Drug Abuse in Schools and Universities. Daily nation.

30. Van Etten ML, Neumark YD, Anthony JC (1999) Male-female differences in the earliest stages of drug involvement. Addiction 94: 1413-1419.

31. Cloninger $\mathrm{R}$ (1983) Genetic and environmental factors in the development of alcoholism. J of PsychTreat and Eval 280: 487-496.

32. Croen LG, Woesner M, Hermann M, Reichgott M (1997) A longitudinal study of substance use and abuse in a single class of medical students. ERIC 72: 376-381.

33. Haworth A (1982) A preliminary report on self-reported drug use among students in Zambia. Bull Narc 34: 45-60.

34. Guy LR (1981) Educational Research: competencies for analysis and application. Charles Mairill Publishing Company Bell A, Howell Company Columbus, Toronto, London.

35. Dhadphale M, Mengech HN, Syme D, Acuda SW (1982) Drug abuse among secondary school students in Kenya: a preliminary survey. East Afr Med J 59: 152-156. 